\title{
Metal oxide-based nanoparticles: revealing their potential to enhance oil recovery in different wettability systems
}

\author{
Luky Hendraningrat $\cdot$ Ole Torsæter
}

Received: 20 February 2014/ Accepted: 17 March 2014/Published online: 30 March 2014

(C) The Author(s) 2014. This article is published with open access at Springerlink.com

\begin{abstract}
This paper presents systematic studies of hydrophilic metal oxide nanoparticles (NPs) dispersed in brine intended to reveal their potential to enhance oil recovery (EOR) in various rock wettability systems. The stability in suspension (nanofluid) of the NPs has been identified as a key factor related to their use as an EOR agent. Experimental techniques have been developed for nanofluid stability using three coupled methods: direct visual observation, surface conductivity and particle size measurements. The use of a dispersant has been investigated and has been shown to successfully improve metal oxide nanofluid stability as a function of its concentration. The dispersant alters the nanofluid properties, i.e. surface conductivity, $\mathrm{pH}$ and particle size distribution. A twophase coreflood experiment was conducted by injecting the stable nanofluids as a tertiary process (nano-EOR) through core plugs with various wettabilities ranging from waterwet to oil-wet. The combination of metal oxide nanofluid and dispersant improved the oil recovery to a greater extent than either silica-based nanofluid or dispersant alone in all wettability systems. The contact angle, interfacial tension (IFT) and effluent were also measured. It was observed that metal oxide-based nanofluids altered the quartz plates to become more water-wet, and the results are consistent with those of the coreflood experiment. The particle adsorption during the transport process was identified from effluent analysis. The presence of NPs and dispersant reduced the IFT, but its reduction is sufficient to yield significant additional oil recovery. Hence, wettability alteration plays
\end{abstract}

L. Hendraningrat $(\bowtie) \cdot$ O. Torsæter

Department of Petroleum Engineering and Applied Geophysics,

Norwegian University of Science and Technology, NTNU,

7491 Trondheim, Norway

e-mail: luky.hendraningrat@ntnu.no a dominant role in the oil displacement mechanism using nano-EOR.

Keywords Enhanced oil recovery - Metal oxide nanoparticles · Characterisation · Nanofluids stability . Wettability alteration

\section{Introduction}

In recent years, most investigations have shown that nanoparticles (NPs) offer promise for future enhanced oil recovery (EOR) processes in which silica-based NPs are most commonly used (Ju et al. 2006; Miranda et al. 2012; Roustaei et al. 2012; Hendraningrat et al. 2013a). Hydrophilic silica NPs were chosen because they consist of greater than $99 \%$ silicon oxide, which is the main constituent of sandstone reservoirs (Hendraningrat et al. 2012). Moreover, silicon oxide is not a chemical that harms the environment. However, inhalation of dried silica NPs into the human body is harmful over a long period. Miranda et al. (2012) mentioned other benefits of using silica NPs for EOR purposes. Silica NPs are an inorganic material that is easy to manipulate in terms of physical chemistry properties. In addition, silica also can be easily surface functionalised from a hydrophobic to hydrophilic state via silanization with hydroxyl groups or sulphonic acid. If the NPs do not aggregate to a larger size, they have the ability to flow through a pore size (typically measured in microns). Hence, the stability of the nanofluid becomes a critical parameter.

The rapid evolution of nanotechnology has created various types of NPs, i.e. metal oxides for multi-purpose applications in many sectors. Currently, metal oxides play an essential role in many areas of chemistry, physics and 
materials science (Fernandez-Garcia and Rodriguez 2007). Metal oxide-based nanofluids are frequently used for thermal conductivity and heat transfer (Fedele et al. 2011; Keblinski et al. 2008; Yu et al. 2008). The most widely used nanometals are $\mathrm{Al}_{2} \mathrm{O}_{3}, \mathrm{MgO}, \mathrm{ZrO}_{2}, \mathrm{CeO}_{2}, \mathrm{TiO}_{2}, \mathrm{ZnO}$ and $\mathrm{Fe}_{2} \mathrm{O}_{3}$, and these metal oxide NPs exhibit unique physical and chemical properties (Fernandez-Garcia and Rodriguez 2007). In the oil and gas industries, the use of metal oxide NPs was recently investigated for trapping and controlling fine migration (Ahmadi et al. 2013; Ogolo et al. 2013) and reducing heavy oil viscosity by acting as a catalyst (Li et al. 2007; Hascakir et al. 2008; Shokrlu and Babadagli 2010).

Because the nanofluid is injected through a typical porous medium with a micron-sized pore throat, it is important to maintain the stability of the nanofluids in terms of nanometer size. Most NPs tend to aggregate once they are hydrated (Keller et al. 2010). The NPs aggregate easily because they have a large ratio of surface area to volume (due to the small particle size); therefore, possess high surface energies and consequently create an aggregate form to minimise these surface energies (Wu et al. 2008). The surface-to-volume ratio is an essential aspect for reactivity, which is defined as the rate at which a chemical reaction will proceed. Materials with a high surface-tovolume ratio react at much faster rates because additional surfaces are available to react. If the NPs create an aggregate form, it may lead to pore throat blocking/plugging and alter the rock properties (Ogolo et al. 2012; Hendraningrat et al. 2013b, c; Ehtesabi et al. 2014).

The classical framework theory used to describe the stability of colloids in suspension (i.e. NPs dispersed in brine as the base fluid) is the DLVO theory (named after Derjaguin, Landau, Verwey and Overbeek). The state of the NPs dispersed in brine is determined by the interactions between the NPs and between the NPs and the base fluid (Rao 2010). This theory primarily addresses the balance between two opposing forces, i.e. van der Waals (VDW) attraction and electrostatic repulsion, to explain why certain colloidal systems agglomerate while others remain discrete and dispersed in suspension. The VDW attraction is the result of forces between individual molecules in each colloid. The electrostatic repulsion becomes significant when two colloids approach each other due to charge interactions, and their double layers begin to interfere. Energy is required to minimise this repulsion by creating an aggregate form. Increasing the repulsive forces by increasing the surface charge between particles provides better stability in the suspension, because it maintains discrete particles and prevents them from gathering into larger sizes in the process known as agglomeration. Each suspension carries the same electrical charge, which produces a force of mutual electrostatic repulsion between adjacent particles. The surface conductivity is closely related to the surface charge. If the charge is sufficiently high, the colloids will remain discrete and dispersed in suspension. Decreasing the charge has the reverse effect. The particle surface charge can be controlled by modifying the suspension liquid, i.e. changing $\mathrm{pH}$, shifting the ionic environment or adding a stabiliser (Rao 2010).

The actual oil reservoirs can be water-, intermediate- or oil-wet. The initial rock wettability will affect oil recovery after waterflooding and plays a vital role in oil production (Morrow 1990). In a water-wet system, the most oil will be produced before water breakthrough after which the rate will decline. Indeed, the water breakthrough will occur earlier in intermediate- or oil-wet systems than in a water-wet system. The wettability affects the relative permeability, which controls the flow and spatial distribution of fluids in a porous medium (Anderson 1987). However, the wettability is not the only parameter that controls the relative permeability curves. Anderson (1987) stated that the relative permeability curves will also be affected by pore geometry, fluid distribution, saturation, and saturation history.

The oil displacement mechanism with use of NPs is not yet clearly understood. Wasan and Nikolov (2003), Chengara et al. (2004), and Wasan et al. (2011) concluded that the structural disjoining pressure is important. The structural disjoining pressure is correlated to the fluid's ability to spread along the surface of a substrate due to an imbalance of the interfacial forces among the solid, oil and aqueous phases (Chengara et al. 2004). The NPs create ordered structures near the three-phase contact line (wetting wedge) of a drop on a solid surface, which promotes spreading of the nanofluid along the surface as monolayer particles. The zero contact angle of the aqueous phase means that the nanofluid has completely spread and has a notably large surface area. Therefore, the fluid possesses a high surface energy with adsorption and alters the surface energy and wettability of the system (Giraldo et al. 2013).

The use of metal oxide nanofluids for EOR purposes that involve stability analysis as well as coreflood experiments with light crude oil and Berea sandstones in various wettability systems has not yet been reported. This paper describes investigation of metal oxide NPs in various initial rock wettability systems to evaluate these materials as alternative solutions for future EOR. Experimental studies on nanofluid stabilities were performed using three techniques: direct visual observation, surface conductivity measurement and particle size analysis. The use of a dispersant in metal oxide NPs was investigated at various concentrations and temperatures. A two-phase coreflood experiment was conducted by injecting those stable nanofluids as a tertiary process (nano-EOR) through Berea sandstone core plugs with various wettability systems ranging from water- to oil-wet. The reason for using different 
wettabilities in this research was to identify the most suitable conditions for each type of NPs. Therefore, the relationship between oil recovery, metal oxide NPs, and initial rock wettability could be identified. The fluid-fluid and rockfluid interactions were analysed via contact angle measurement, interfacial tension (IFT) measurement and effluent analysis to observe possible oil displacement mechanisms.

\section{Experiments}

Fluids

Degassed crude oil from a field in the North Sea was used as the oleic phase in this study. This oil has a viscosity of

Table 1 Fluid properties at room condition

\begin{tabular}{lllll}
\hline Fluid & $\begin{array}{l}\text { Density } \\
\left(\mathrm{g} / \mathrm{cm}^{3}\right)\end{array}$ & $\begin{array}{l}\text { Viscosity } \\
(\mathrm{cP})\end{array}$ & $\mathrm{pH}$ & $\begin{array}{l}\text { Surface } \\
\text { Conductivity } \\
(\mathrm{mV})\end{array}$ \\
\hline Degassed crude oil & 0.826 & 5.10 & - & - \\
$\mathrm{Brine}, \mathrm{NaCl} \mathrm{3}$ wt \% & 1.022 & 1.001 & 6.76 & 14.2 \\
$\mathrm{Al}_{2} \mathrm{O}_{3}$ nanofluid 0.05 wt \% & 1.020 & 1.03 & 6.551 & 29.0 \\
$\mathrm{TiO}_{2}$ nanofluid 0.05 wt \% & 1.016 & 1.08 & 6.413 & 36.6 \\
$\mathrm{SiO}_{2}$ nanofluid 0.05 wt \% & 1.020 & 1.02 & 6.220 & 49.9 \\
\hline
\end{tabular}

Table 2 Nanoparticles properties

\begin{tabular}{llll}
\hline Properties & $\mathrm{Al}_{2} \mathrm{O}_{3}$ & $\mathrm{TiO}_{2}$ & $\mathrm{SiO}_{2}$ \\
\hline Specific surface area, BET $\left(\mathrm{m}^{2} / \mathrm{g}\right)$ & $65 \pm 10$ & $50 \pm 15$ & $45-60$ \\
Declared primary particle size $(\mathrm{nm})$ & 17 & 21 & 40 \\
Bulk density (g/L) & 50 & 130 & $90-110$ \\
$\mathrm{pH}(4-5 \%$ in dispersion) & $4.5-6$ & $3.5-4.5$ & $3.8-4.8$ \\
\hline
\end{tabular}
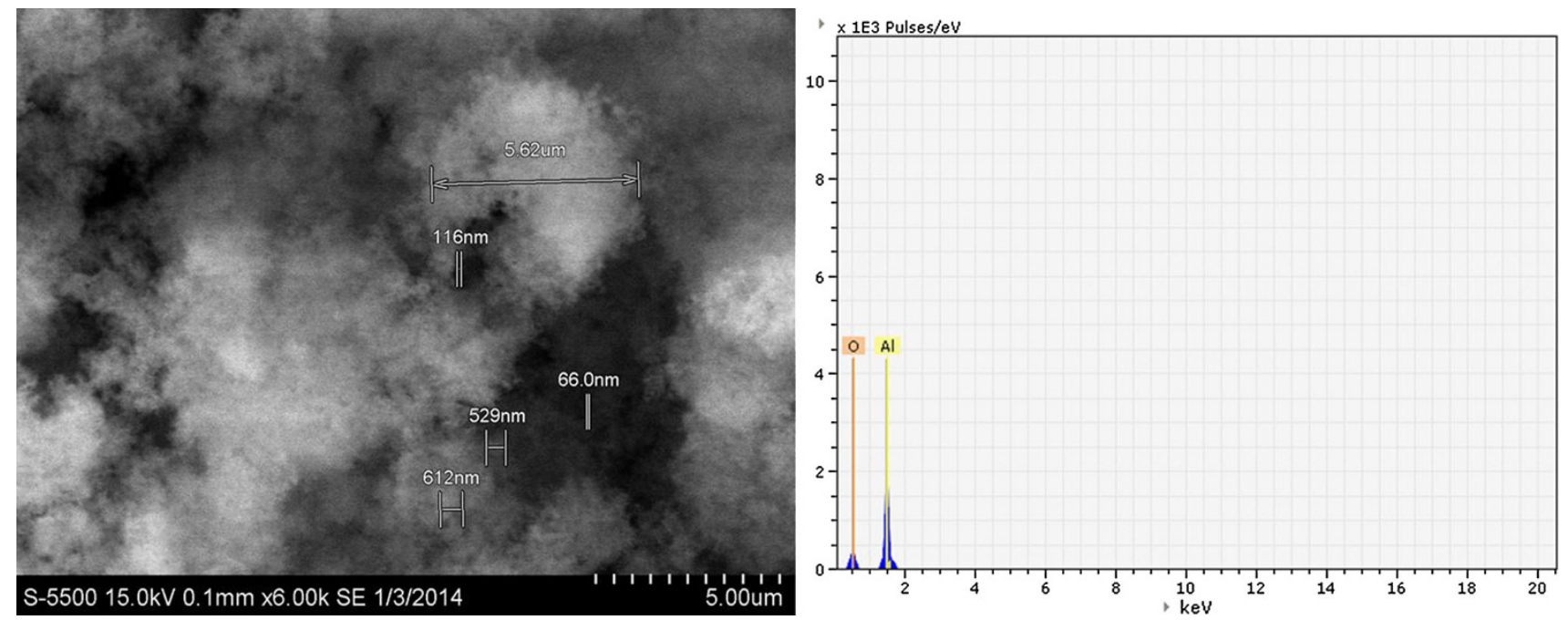

Fig. 1 Morphology and elemental analysis of $\mathrm{Al}_{2} \mathrm{O}_{3}$ NPS from SEM-integrated EDX instrument approximately $5.1 \mathrm{cP}$ at $22{ }^{\circ} \mathrm{C}$. For the base aqueous phase, a synthetic reservoir brine was prepared from sodium chloride $(\mathrm{NaCl})$ at 3.0 wt. \% (approx. 30,000 ppm) and deionised water. The density and viscosity were measured using a pycnometer and a Brookfield rotating viscometer (model LVDV-II $+\mathrm{P}$ ), respectively. The $\mathrm{pH}$ and surface conductivity were measured using a digital $\mathrm{pH}$ meter Metroohm (serial 827). This brine was used as the dispersion fluid for the NPs, and the fluid properties are summarised in Table 1. Adding NPs into the brine slightly decreased its density and $\mathrm{pH}$ value, whereas the viscosity and surface conductivity were increased.

\section{Nanoparticle preparation and characterisation}

Three fumed hydrophilic oxide NPs, i.e. aluminium $\left(\mathrm{Al}_{2} \mathrm{O}_{3}\right)$, titanium $\left(\mathrm{TiO}_{2}\right)$, and silica $\left(\mathrm{SiO}_{2}\right)$, were employed in this study. These NPs were selected due to similar specific surface areas (Brunauett-Emmett-Teller/BET) of approximately $45-65 \mathrm{~m}^{2} / \mathrm{g}$. The average primary particle sizes of those NPs were declared as $17 \mathrm{~nm}$ for $\mathrm{Al}_{2} \mathrm{O}_{3}$, $21 \mathrm{~nm}$ for $\mathrm{TiO}_{2}$ and $40 \mathrm{~nm}$ for $\mathrm{SiO}_{2}$. Table 2 lists the properties of the NPs. Characterisation and elemental analysis of NPs were carried out using a scanning electron microscope (SEM, Hitachi Model S-5500) and integrated energy-dispersive X-ray spectroscopy (EDX), as shown in Figs. 1, 2, 3. The carbon appears because the NPs were placed on carbon conductive tape. Based on this characterisation, the NPs took on a secondary form after aggregation under SEM that is much larger than their primary particle size. As explained in the previous section, the NPs easily aggregate because they have a large surface-to-volume ratio (due to the small particle size) and therefore possess high surface energies. The NPs consequently create 
an aggregate form to minimise this surface energy. In addition, materials with high surface-to-volume ratios react at much faster rates because additional surfaces are available to react. To obtain a more precise particle size characterisation, the NanoSight instrument was used, which operates based on a conventional optical microscope concept but uses a laser light source to illuminate nano-sized particles within a sample introduced to the viewing unit via a disposable syringe, and the particles subsequently scatter the light. The detector measures the NPs in a particular area (Nanosight 2009).

\section{Nanofluid preparation and characterisation}

Each type of NP was synthesised using brine with a weight concentration of 0.05 wt. \%. This concentration was selected based on our previous concentration optimisation study of silica NPs (Hendraningrat et al. 2013c). The nanofluids were synthesised using highspeed magnetic stirring and ultra-sonication at 60-100\% amplitude. The fluid properties of the nanofluids are provided in Table 1. Figure 4 shows brine $(\mathrm{NaCl} 3$ wt. \%) containing NPs at 0.05 wt. $\%$ at the initial condition. Of the group, the $\mathrm{TiO}_{2}$ nanofluid is the milkiest in appearance due to original colour from the particles. The characterisation of NP sizes and distributions dispersed in brine were measured using nanoSight. Figure 5 shows the NP distribution measurements dispersed in brine, ranging from $0 \mathrm{~nm}$ to greater than $1,000 \mathrm{~nm}$ in particle size. The means of the NP diameters measured from NanoSight are $98 \mathrm{~nm}$ for $\mathrm{Al}_{2} \mathrm{O}_{3}, 106 \mathrm{~nm}$ for $\mathrm{TiO}_{2}$ and $53 \mathrm{~nm}$ for $\mathrm{SiO}_{2}$.
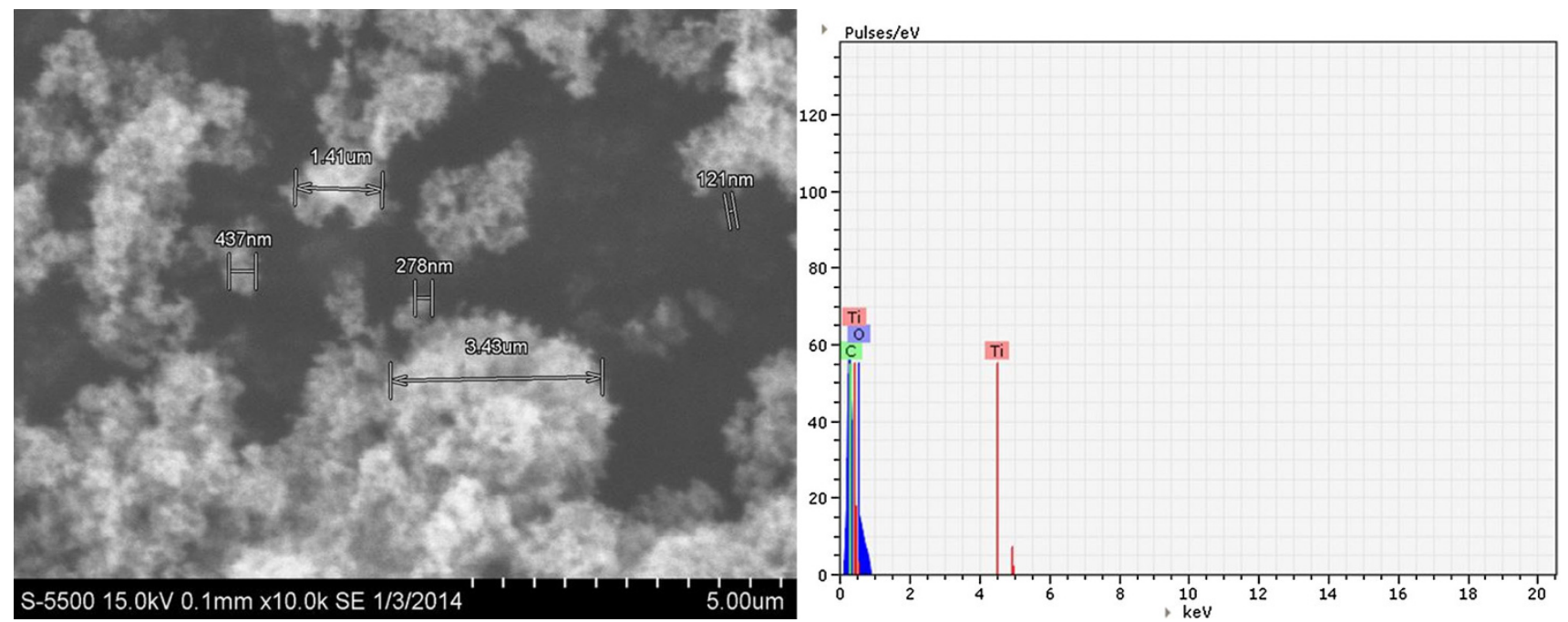

Fig. 2 Morphology and elemental analysis of $\mathrm{TiO}_{2}$ NPS from SEM-integrated EDX instrument
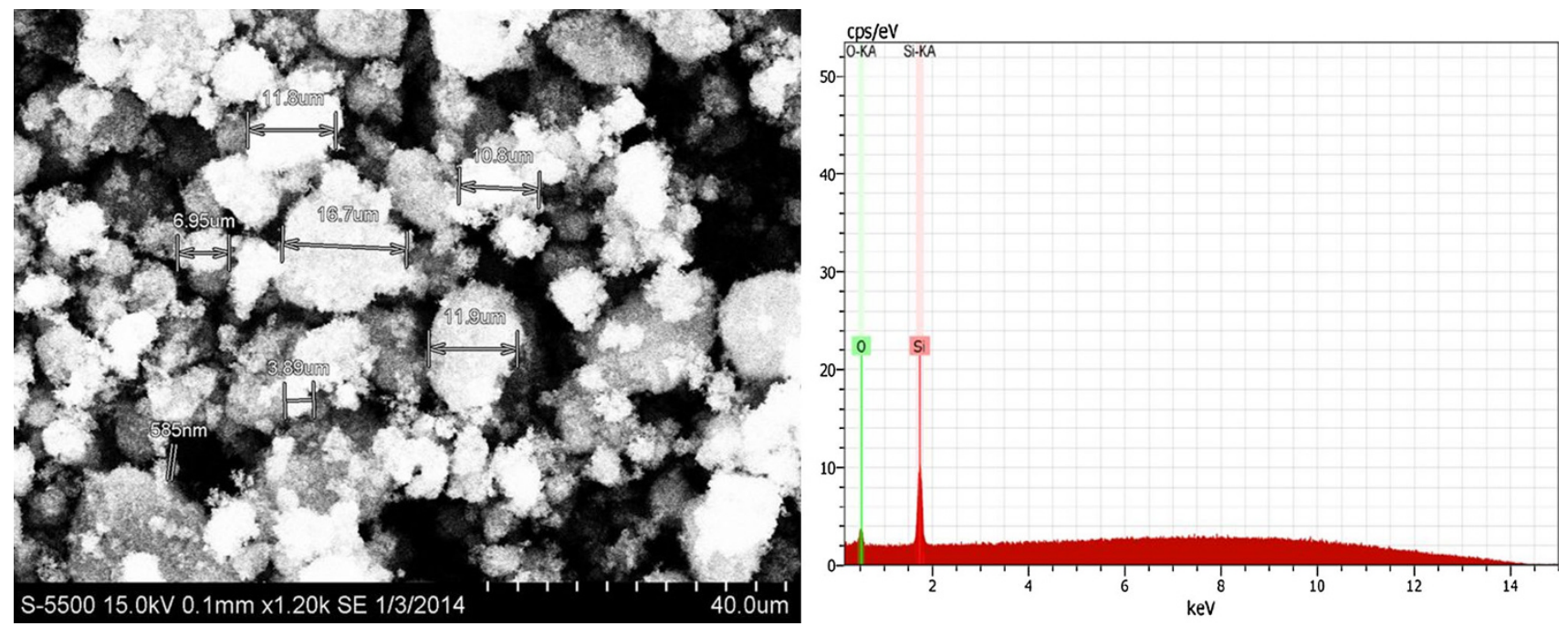

Fig. 3 Morphology and elemental analysis of $\mathrm{SiO}_{2}$ NPS from SEM-integrated EDX instrument 
Nanofluid stabilising agent

A polyvinylpyrrolidone (PVP) stabiliser known as Povidone is used in this study. This material has an ultrafine amorphous form, a size of approximately 50-250 $\mu \mathrm{m}$ and a bulk density of 400-600 g/L (Folttmann and Quadir 2008). The molecular form of PVP is $\left(\mathrm{C}_{6} \mathrm{H}_{9} \mathrm{NO}\right)_{n}$, and the chemical structure of PVP is shown in Fig. 6. An

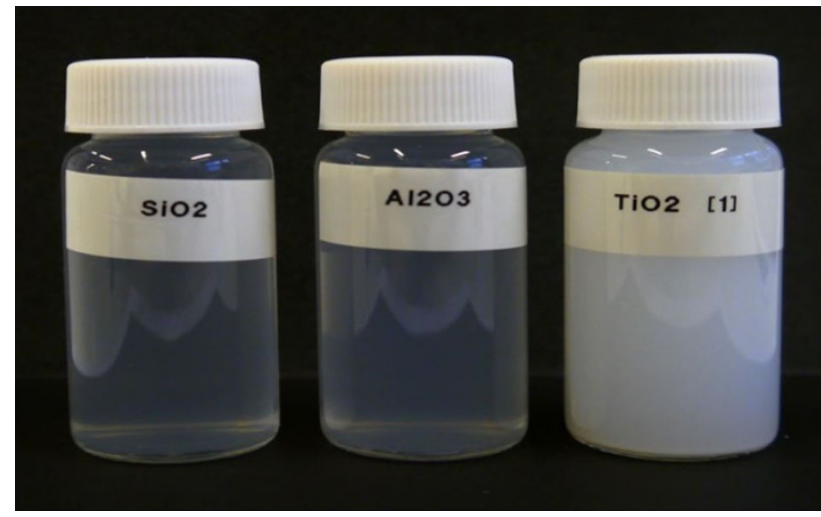

Fig. 4 Brine $(\mathrm{NaCl} 3$ wt \%) containing nanoparticles 0.05 wt $\%$ at initial condition advantage of PVP is its universal solubility both in hydrophilic and hydrophobic solvents (Folttmann and Quadir 2008), and it is a non-toxic stabiliser that is safe for the environment. Currently, PVP is widely used as a binder for capsules and granules (especially in pharmaceuticals), a film former in medical plastics, a taste masker in chewable tablets and a toxicity reducer (Folttmann and Quadir 2008). In this study, PVP type K30 was added to avoid earlier NP aggregation by improving the metal oxide nanofluid stability. The K30 refers to the $K$ value of this PVP in the range 27.0-32.4. The $K$ value characterises the mean molecular weight of PVP, and the higher the $K$ values, the higher the molecular weight.

Core preparation and characterisation

All cores used in this study consisted of Berea sandstone, which is commonly used as a sandstone core porous medium in most laboratory research. The core has an average diameter and length of 3.8 and $4.0 \mathrm{~cm}$, respectively. All cores were first cleaned with methanol and dried in a heating cabinet at $80{ }^{\circ} \mathrm{C}$ for $2-3$ days until no dry weight alteration was observed before and after cleaning based on standard laboratory procedure (Torsæter and
Fig. 5 NanoSight measurement of nanoparticles size distribution for brine $(\mathrm{NaCl} 3$ wt $\%$ ) containing 0.05 wt $\%$ nanoparticles at initial condition
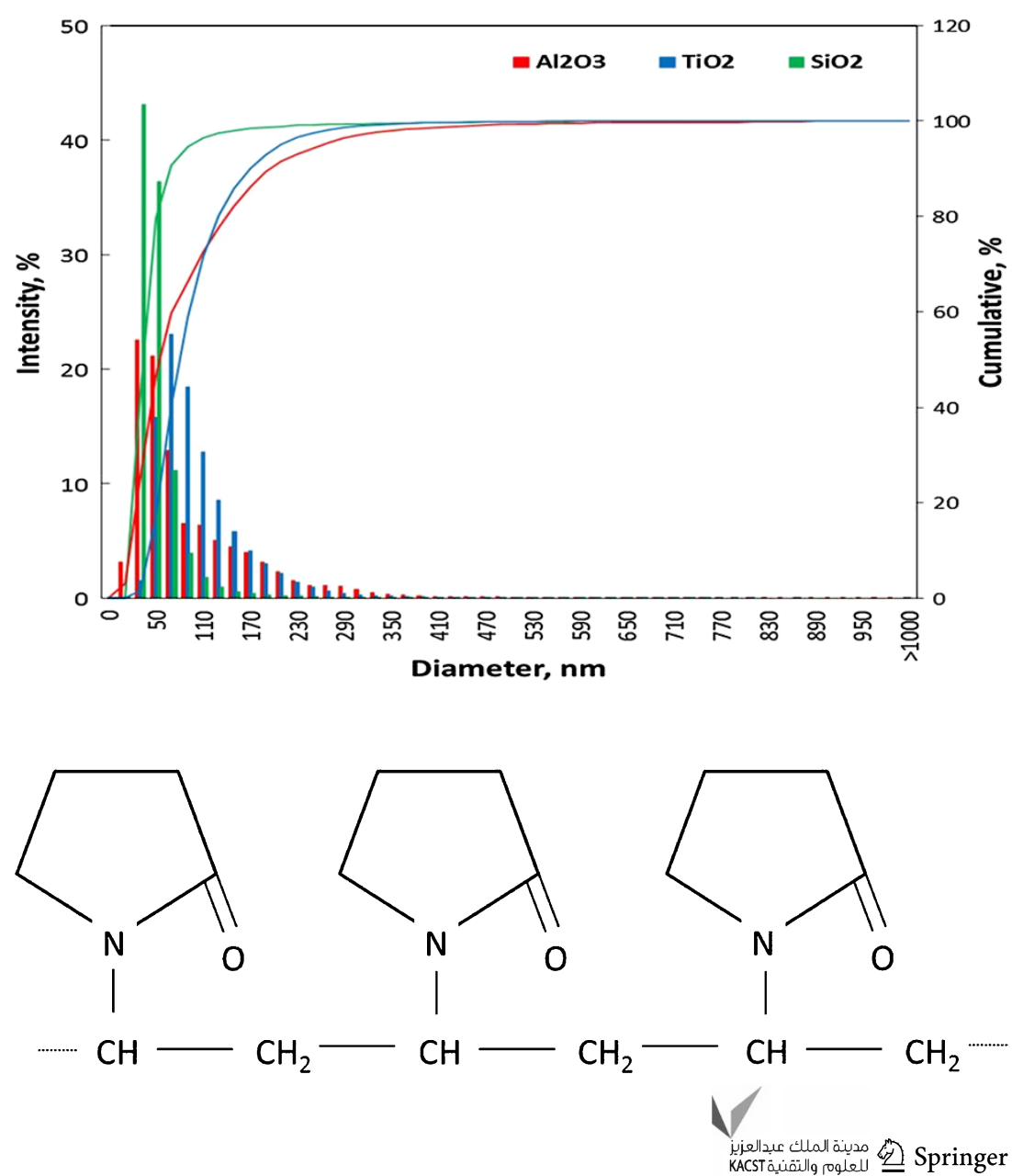

Fig. 6 Chemical structure of PVP (Adapted from Folttmann and Quadir 2008) 
Abtahi 2003). The porosities were measured using a helium porosimeter, resulting in values from 15 to $17 \%$. Selected cores were cut into smaller specimens for characterisation purposes. Others were used in further ageing processes to alter the original wettability from water-wet to intermediate- and oil-wet systems. The pore size of Berea sandstone was observed using SEM, which reported micron-sized pores, as shown in Fig. 7.

The core mineralogy was characterised using two methods: energy-dispersive X-ray (EDX) and X-ray diffraction (XRD). Figure 8 shows the EDX elemental analysis of areas A and B. The only elements present in both locations are $\mathrm{Si}, \mathrm{O}, \mathrm{Al}$ and $\mathrm{K}$. Reactive clays such as ' $\mathrm{Na}^{+}$,, $\mathrm{Ca}^{+2}$, ${ }^{\prime} \mathrm{Cl}^{-}$, , or ' $\mathrm{Mg}^{+2}$, were not identified based on this analysis, but a minor amount of those elements

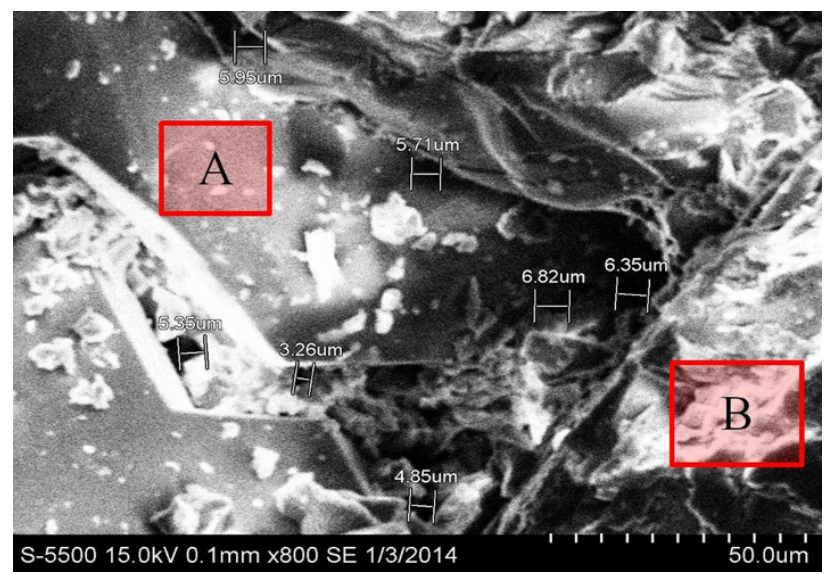

Fig. 7 Morphology of Berea sandstone SEM image with pore size identification may be present. Table 3 provides the XRD analysis data from four samples and shows consistent results. The core was dominated by quartz, which is composed of elements $\mathrm{Si}$ and $\mathrm{O}(91-93 \%)$. The potassium $\left(\mathrm{K}^{+}\right)$and aluminium $\left(\mathrm{Al}^{+3}\right)$ may originate from either alkali feldspar (KAl$\left.\mathrm{Si}_{3} \mathrm{O}_{8}\right)$ or residues. The minor residue is identified as pyroxene, which has the general formula XYZ2O6, where $X=\mathrm{Mg}^{+2}, \mathrm{Fe}^{+2}, \mathrm{Mn}^{+2}, \mathrm{Li}^{+}, \mathrm{Ca}^{+2}, \mathrm{Na}^{+} ; Y=\mathrm{Al}^{+3}$, $\mathrm{Fe}^{+3}, \mathrm{Cr}^{+3}, \mathrm{Cr}^{+3}, \mathrm{Ti}^{+4}, \mathrm{Mg}^{+2}, \mathrm{Fe}^{+2}, \mathrm{Mn}^{+2}$; and $Z=\mathrm{Si}$, $\mathrm{Al}^{+3}, \mathrm{Fe}^{+3}$. The XRD results are consistent with the EDX results. Hence, it was assumed that the obtained mineralogy is representative for all core plugs studied in this work.

\section{Quartz plate preparation}

A series of rectangular transparent plates of quartz was used as the solid substrates in this study. Each quartz plate has average dimensions of $2.8 \mathrm{~cm}$ in length, $1.5 \mathrm{~cm}$ in width and $0.19 \mathrm{~cm}$ in height. The quartz plates were first cleaned with a detergent solution and rinsed with methanol followed by distilled water. The plates were dried in a heating cabinet at $50-60{ }^{\circ} \mathrm{C}$ for $3-5$ days. The original wettability of the quartz plate was observed by measuring the contact angle between brine and crude oil and is considered as water-wet (Hendraningrat et al. 2013a).

Nanofluid stability analysis

Nanofluid stability analysis was carried out using three coupled techniques: direct visual observation, surface conductivity measurement and NanoSight. The visual
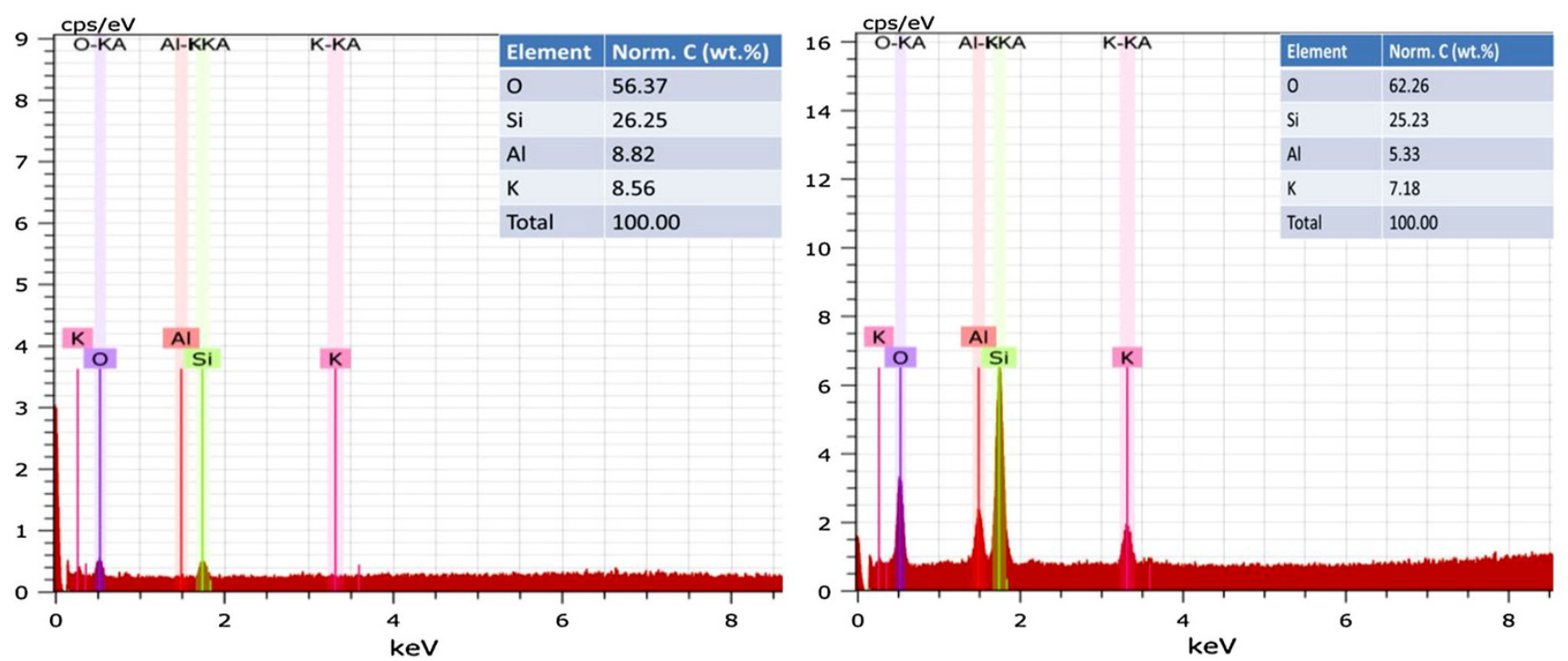

Fig. 8 Quantitative mineral elements analysis using EDX integrated with SEM at area $A($ left $)$ and $B$ (right) 
Table 3 XRD mineral analysis of Berea core plugs (\% mass)

\begin{tabular}{lllll}
\hline Mineral & Sample-1 & Sample-2 & Sample-3 & Sample-4 \\
\hline Quartz & 93 & 91 & 92 & 93 \\
Alkali feldspar & 6 & 8 & 8 & 7 \\
Pyroxene & $<1$ & $<1$ & $<1$ & $<1$ \\
\hline
\end{tabular}

observation was conducted at various temperatures: room temperature, 50 and $80{ }^{\circ} \mathrm{C}$. The dispersant PVP was used and studied to avoid early metal oxide NP aggregation. Three different concentrations of PVP were studied: 0.1, 0.5 and $1.0 \mathrm{wt} \%$. The surface conductivity of each nanofluid solution was measured using a digital $\mathrm{pH}$ meter. Each colloid carries a "like" surface charge that produces a force of mutual electrostatic repulsion between adjacent particles. The surface conductivity is closely related to the surface charge. If the charge is sufficiently high, the colloids will remain in discrete form and exhibit good stability in suspension. Decreasing the surface charge has the reverse effect. The particle stability also can be observed using NanoSight. The nanofluids will be unstable if particles aggregate and create a secondary form that is larger than the primary particle size. NanoSight is a useful technique for identifying the particle size and its distribution in solution.

\section{Wettability alteration via an ageing process}

The original wettability of the cores and quartz plates was altered from water-wet to intermediate- and oil-wet via an ageing process. The wettability of porous rock was determined using the Amott test, which combines spontaneous and forced displacement at room conditions with a wettability index $\left(I_{\mathrm{W}}\right)$ formula as follows:

$I_{\mathrm{w}}=\frac{V_{\mathrm{o} 1}}{V_{\mathrm{o} 1}+V_{\mathrm{o} 2}}-\frac{V_{\mathrm{w} 1}}{V_{\mathrm{w} 1}+V_{\mathrm{w} 2}}$ where $V_{\mathrm{o}}$ describes the oil volume produced from the imbibition process, $V_{\mathrm{w}}$ describes the water volume from the drainage process, subscript ' 1 ' denotes a spontaneous displacement process and ' 2 ' indicates a forced displacement process.

The wettability index $\left(I_{\mathrm{W}}\right)$ of a porous medium can be correlated with the contact angle obtained from a smooth surface by the inversed cosine (arccos) of the contact angle. A water-wet system is represented by an $I_{\mathrm{W}}$ from +0.25 to +1.0 (contact angle from $0^{\circ}$ to $75^{\circ}$ ), intermediate-wet by an $I_{\mathrm{W}}$ from -0.25 to +0.25 (contact angle from $75^{\circ}$ to $105^{\circ}$ ) and oil-wet by an $I_{\mathrm{W}}$ from -0.25 to -1.0 (contact angle from $105^{\circ}$ to $180^{\circ}$ ). The original wettabilities of the Berea sandstone cores show an Amott-Harvey wettability index $\left(I_{\mathrm{W}}\right)$ ranging from +0.7 to +0.9 and are considered as strongly water-wet (Hendraningrat et al. 2013d). Ageing in crude oil altered the Berea core plugs to intermediatewet. The ageing process took approximately 4 weeks at temperatures of $80-90{ }^{\circ} \mathrm{C}$ and altered the core wettability $I_{\mathrm{W}}$ to an average of +0.05 ( $\mathrm{Li}$ et al. 2013). At the same time, a mixture of $70 \%(\mathrm{~V} / \mathrm{V})$ Pentane $\left(\mathrm{C}_{5}-\mathrm{H}_{12}\right)$ and $30 \%$ (V/V) Surfasil ${ }^{\mathrm{TM}}\left(\mathrm{C}_{8}-\mathrm{H}_{24}-\mathrm{Cl}_{2}-\mathrm{O}_{3}-\mathrm{Si}_{4}\right)$ was used to alter the core and quartz plate wettability from water-wet to oilwet. Surfasil ${ }^{\mathrm{TM}}$ can be used for surface treatment purposes. The latter process took approximately 6 days at room temperature. Based on the Amott test, the substrate has an $I_{\mathrm{W}}$ in the range from -0.5 to -0.6 and is considered oilwet.

\section{Contact angle measurement}

The contact angle was measured directly on transparent quartz plates using a Goniometry KSV CAM instrument at ambient conditions. The system consists of a quartz plate as the solid, a degassed crude oil from a field in the North Sea as the oleic phase and nanofluids as the aqueous phase, as shown in Fig. 9. The measurement is based on the Young-Laplace formula as follows:
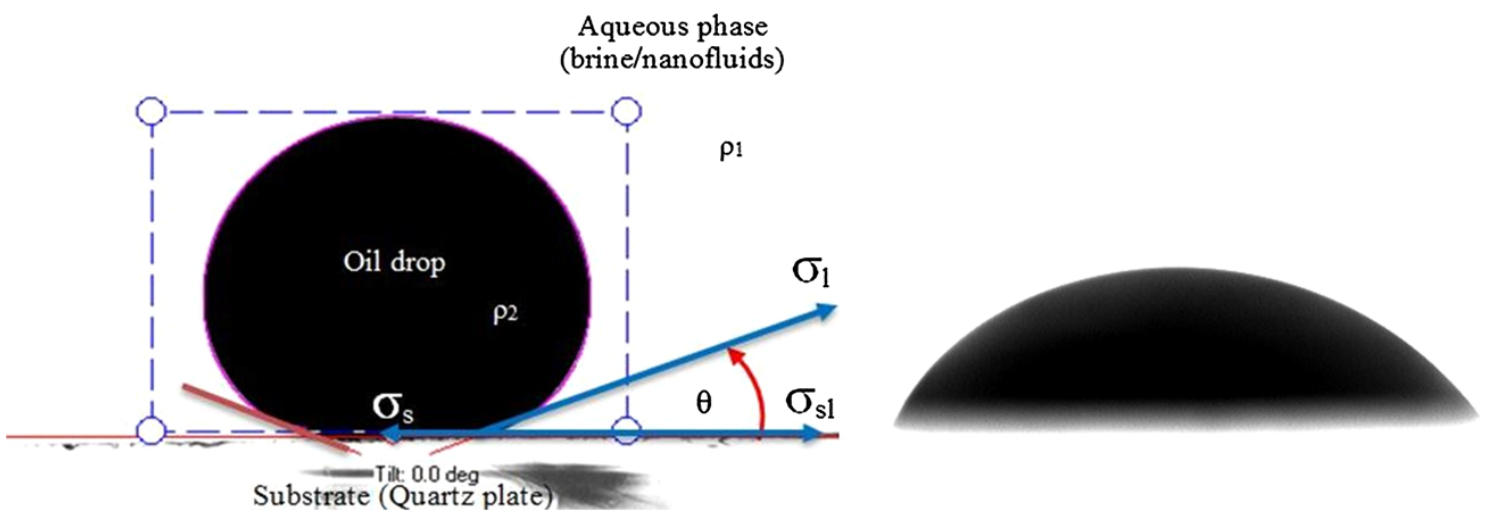

Fig. 9 Contact angle formation on quartz glass of crude oil against brine/nanofluids: water-wet system (left) and oil-wet (right) 


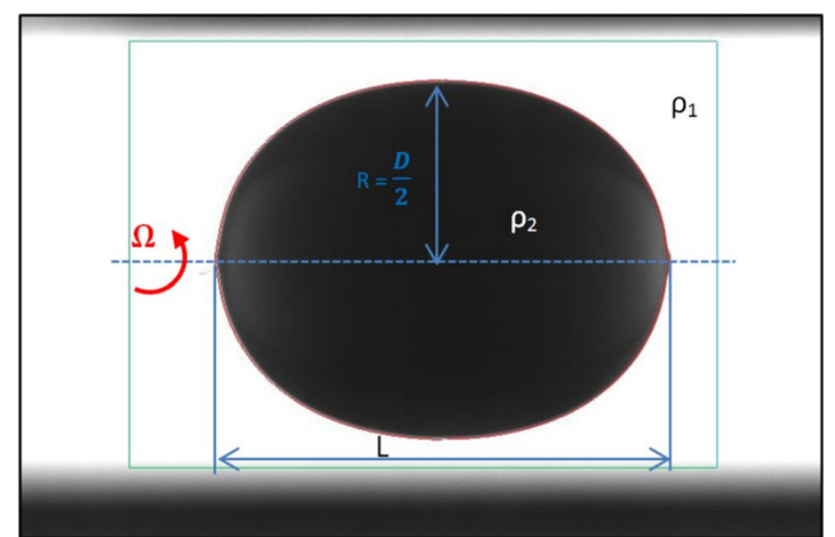

Fig. 10 Interfacial tension measurement between crude oil and brine/ nanofluid

$\sigma_{\mathrm{s}}=\sigma_{\mathrm{sl}}+\sigma_{\mathrm{l}} \cos \theta$

where $\sigma$ describes the interfacial tension components of phase, indices $\mathrm{s}$ and 1 stand for the solid and liquid phases, respectively, $\sigma_{\mathrm{s} 1}$ represents the interfacial tension between the two phases and $\theta$ is the contact angle corresponding to the angle between vectors $\sigma_{1}$ and $\sigma_{\mathrm{sl}}$.

Treiber et al. (1971) defined the contact angle in a threephase system (water, oil and rock surface) as follows: water-wet in the range of $0^{\circ}-75^{\circ}$, intermediate/neutral-wet in the range of $75^{\circ}-105^{\circ}$ and oil-wet in the range of $105^{\circ}-$ $180^{\circ}$. A zero contact angle indicates that the denser fluid completely wets the solid.

\section{Interfacial tension measurement}

The interfacial tension (IFT) of degassed crude oil was measured against brine/nanofluids as the aqueous phase using a SVT20 spinning drop video tensiometer at room temperature, as shown in Fig. 10. This measurement involves crude oil with brine and silica-based and $\mathrm{Al}_{2} \mathrm{O}_{3}$ based nanofluids with PVP. Due to poor clarity, the IFT of the $\mathrm{TiO}_{2}$-based NPs with PVP nanofluid could not be measured. The rotational speed was maintained near $5,000-6,000 \mathrm{rpm}$. The formula used to measure IFT is as follows (Than et al. 1988):

$\sigma=\frac{\Delta \rho \times \Omega^{2} \times\left(D_{\text {app }}\right)^{3}}{8 n^{3} J_{\mathrm{D}}\left(\frac{L}{D}\right)}$

where $\sigma$ is the interfacial tension $(\mathrm{dyn} / \mathrm{cm}), \Delta \rho$ is the density difference $\left(\mathrm{g} / \mathrm{cm}^{3}\right), \Omega$ is the rotational rate of the cylinder $\left(\mathrm{s}^{-1}\right), D_{\text {app }}$ is the measured drop diameter $(\mathrm{cm}), n$ is the refractive index of the heavy fluid, $D$ is the true diameter of the drop $\left(\mathrm{D}=\frac{D_{\text {app }}}{n}\right), J_{\mathrm{D}}$ is a correction factor and a function of $L / D$, and $L / D$ is the aspect ratio (e.g. the ratio of the drop length to its diameter).
Coreflood procedure

All cores were fully saturated with brine in a vacuum container for approximately 1-2 days. The liquid (brine) permeability of cores was measured with a range of $100-400 \mathrm{mD}$. The two-phase oil-water system coreflooding instrument is shown in Fig. 11. The sleeve pressure was set to a constant 20 bar in the Hassler core cell. The drainage process was started by injection of degassed crude oil at a flowrate from 1 to $40 \mathrm{~cm}^{3} / \mathrm{min}$ with approximately 8-10 of pore volume (PV) until no more brine was produced and thus the initial water saturation was established. As a first forced imbibition process, brine (denoted as WF1) was injected at a constant rate of $0.2 \mathrm{~cm}^{3} / \mathrm{min}$ with a range of 3-5 PV into the core plugs until no more oil was produced and thus residual oil saturation was established due to waterflooding. The injection rate was chosen to approximate the typical reservoir velocities. Next, the injection was continued at a similar injection rate and pore volume of nanofluids (silica and metal oxides) as a tertiary recovery process (denoted as NF). In the final stage, brine was re-injected (denoted as WF2) in a range of 3-5 PV under the same conditions as those of previous flooding. The recovered oil was accumulated into a gravity-settling separator and calculated based on material balance. A camera was installed to record the oil recovery during the flooding process, and the effluents were collected in a water accumulator. For each sequential flooding process, the effluent was collected at the last PV to analyse its $\mathrm{pH}$ and surface conductivity alterations to avoid contamination from the previous sequence. A differential pressure transmitter in the range of 0-30 bar was connected to the inlet and outlet ends of the core holder to measure and record the pressure drop across the core during the flooding process. The data were recorded into a computer in real time. As a comparison, brine with dispersant alone was used in the tertiary flooding and is discussed in the following section.

\section{Results and discussion}

Nanofluid stability analysis

Providing a stable nanofluid is challenging, because NPs have a tendency to aggregate due to forces of different natures that interact amongst particles and may lead to agglomeration (Fedele et al. 2011). Decreasing the stability of nanofluids will reduce their advantages. We observed that nanofluid stability has been observed as a critical issue prior to use as EOR agents (Hendraningrat et al. 2013b). The stability of nanofluids is a function of its concentration as dispersed in brine. During the injection process, the tendency of NPs to agglomerate will affect the porosity and 


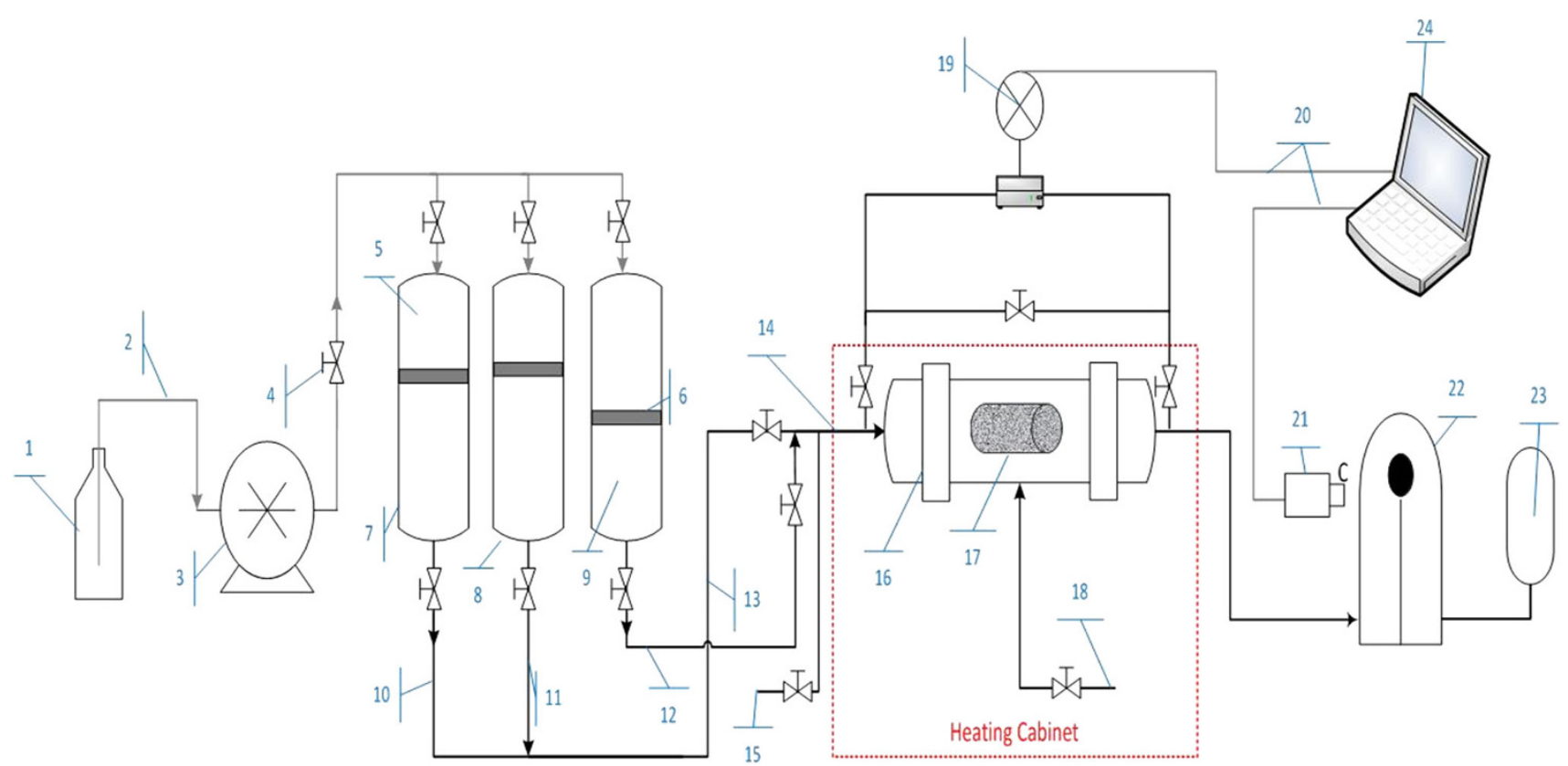

Fig. 11 Experimental setup schematic 1 pump fluid (Exxol D60), 2 injection pipe (ID $1.5 \mathrm{~mm}$ ), 3 pump, 4 valve, 5 pump fluid in vesselA, 6 piston plate, 7 brine in vessel-A, 8 nanofluid in vessel-B, 9 crude oil in vessel-C, 10 brine pipeline, 11 nanofluid pipeline, 12 oil pipe, 13 water-phase pipeline, 14 inlet pipeline, 15 bypass valve, 16 Hassler core cell inside oven, 17 core plug inside cell, 18 sleeve pressure, 19 pressure transmitter, 20 connection cable to $\mathrm{PC}, 21$ camera recorder, 22 oil-water separator, 23 water accumulator, 24 Computer/PC as controller and data acquisition
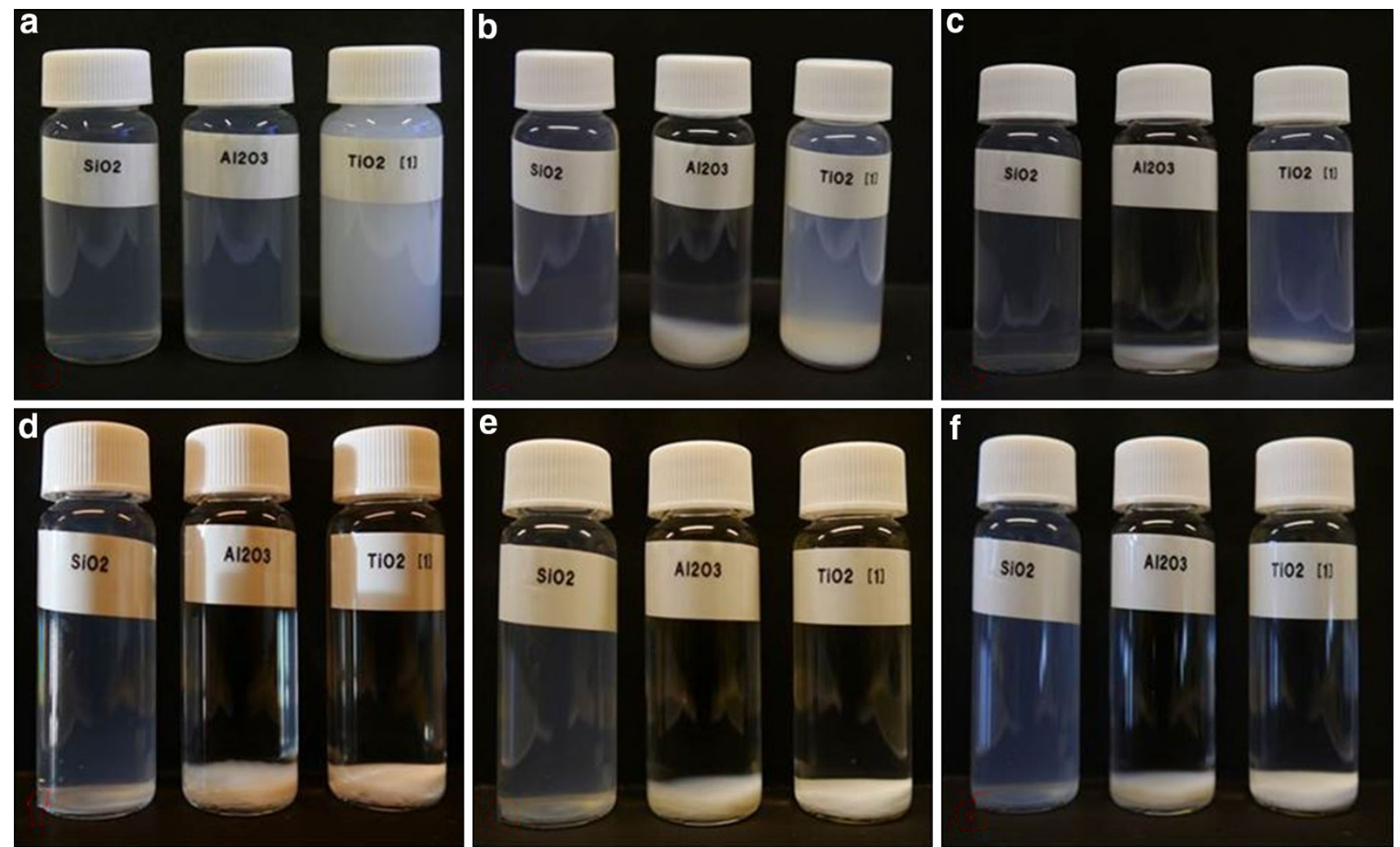

Fig. 12 Untreated nanofluids stability observations at room condition: a initial condition, b $t=1 \mathrm{~h}, \mathbf{c} t=3 \mathrm{~h}, \mathbf{d} t=24 \mathrm{~h}, \mathbf{e} t=48 \mathrm{~h}$, f $t=168 \mathrm{~h}$ 

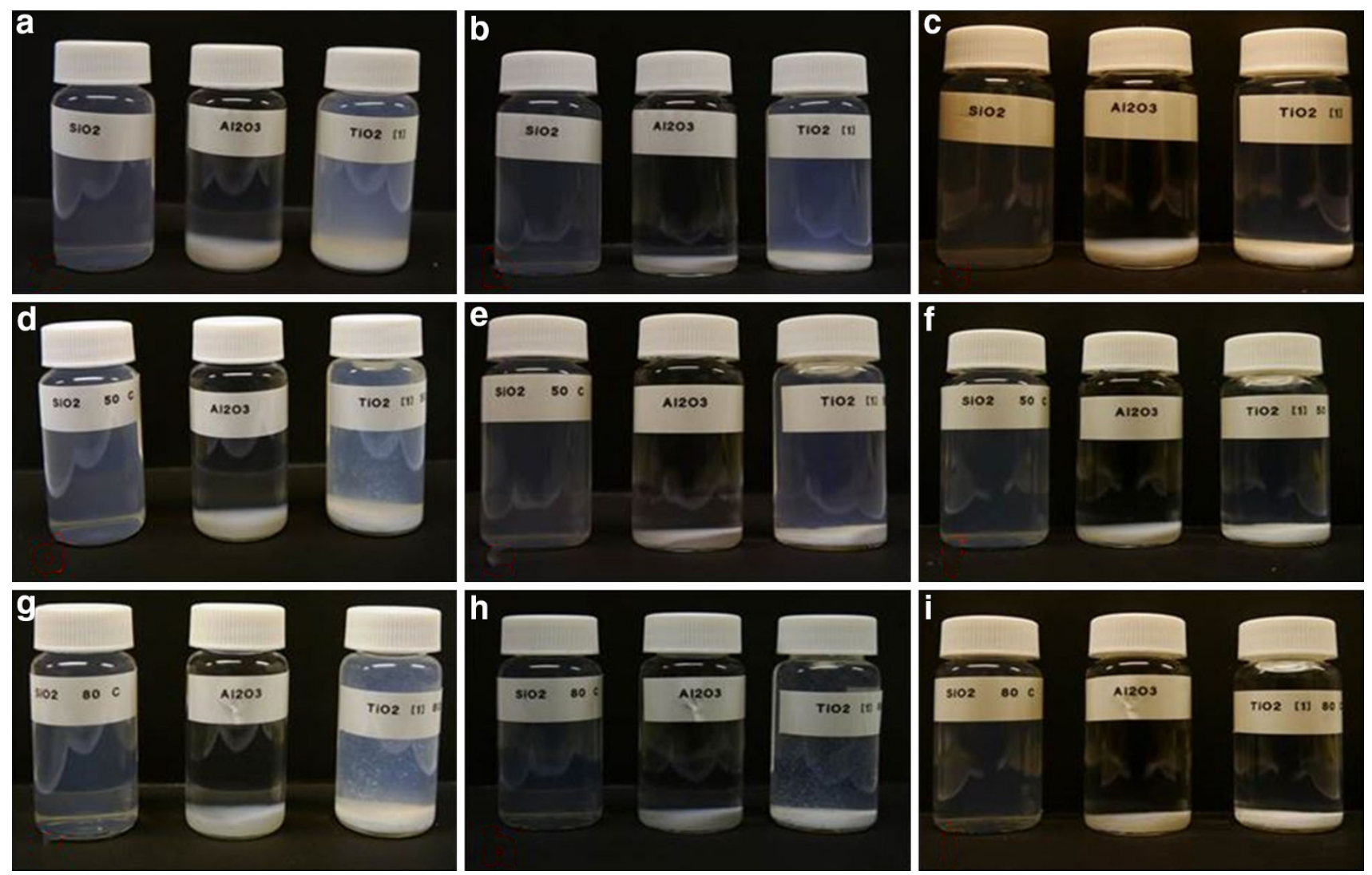

Fig. 13 Untreated nanofluids stability observations at various temperatures: $25{ }^{\circ} \mathrm{C}$ (top row), $50{ }^{\circ} \mathrm{C}$ (middle row), $80{ }^{\circ} \mathrm{C}$ (bottom row). The observation were taken at; $1 \mathrm{~h}$ (first column); $3 \mathrm{~h}$ (second column) and $8 \mathrm{~h}$ (third column)

impair permeability. It was also observed that oil recovery is not proportional to the nanofluid concentration, which means that oil recovery is enhanced if the nanofluid concentration increases but decreases if the concentration is higher than a critical value. For oil recovery, the critical value seems to be an optimum hydrophilic nanofluid concentration of 0.05 wt. \%, and we selected this concentration in this study. The nanofluid stability analysis was developed using three techniques: direct visual observation, surface conductivity measurement and particle size analysis.

Based on our visual observation of stability over $168 \mathrm{~h}$, as shown in Figs. 12, 13, untreated hydrophilic metal oxide NPs (0.05 wt. \%) were much easier to precipitate than silica dioxide when dispersed in brine solution. As shown in Fig. 12, these particles began to precipitate in less than $1 \mathrm{~h}$ at room conditions. The $\mathrm{A}_{2} \mathrm{O}_{3}$-based nanofluid was completely precipitated after approximately $3 \mathrm{~h}$, and the $\mathrm{TiO}_{2}$-based nanofluid agglomerated slightly later (Fig. 13). The $\mathrm{SiO}_{2}$-based nanofluids show much better stability over approximately $24-48 \mathrm{~h}$. Thermal stability was also observed at room temperature, 50 and $80{ }^{\circ} \mathrm{C}$, as shown in Fig. 14, to determine the stability in reservoir temperature conditions. The behaviour appears analogous for metal oxides at room conditions, which means that the higher temperature does not significantly affect the NP aggregation. These visual stability observations are consistent with the surface conductivity measurements, as shown in Table 1. The $\mathrm{SiO}_{2}$-based nanofluid has the highest surface conductivity $(49.9 \mathrm{mV})$ among the nanofluids, whereas the $\mathrm{Al}_{2} \mathrm{O}_{3}$-based nanofluid has the lowest $(29 \mathrm{mV})$. The surface conductivity is inversely related to the $\mathrm{pH}$ value, and the higher the particle charge potential, the more stable is the nanofluid. The surface conductivity is closely related to the surface charge. If the charge is sufficiently high, the colloids will remain discrete and dispersed in suspension.

Determination of the mean particle size dispersed in brine was carried out using NanoSight, as shown in Fig. 5, and the results are summarised as follows: $98 \mathrm{~nm}$ for $\mathrm{Al}_{2} \mathrm{O}_{3}, 106 \mathrm{~nm}$ for $\mathrm{TiO}_{2}$ and $53 \mathrm{~nm}$ for $\mathrm{SiO}_{2}$. Although the $\mathrm{SiO}_{2}$ nanoparticle has the largest primary particle size $(40 \mathrm{~nm})$ among the NPs used in this study (see Table 2), its mean diameter is the smallest when dispersed in brine (Fig. 15). The $\mathrm{Al}_{2} \mathrm{O}_{3}$ NPs have the highest degree of aggregation, almost six times larger than the primary particle size. These results are consistent with those from two previous techniques in which $\mathrm{Al}_{2} \mathrm{O}_{3}$-based nanofluid precipitated fastest and had the lowest surface conductivity. 

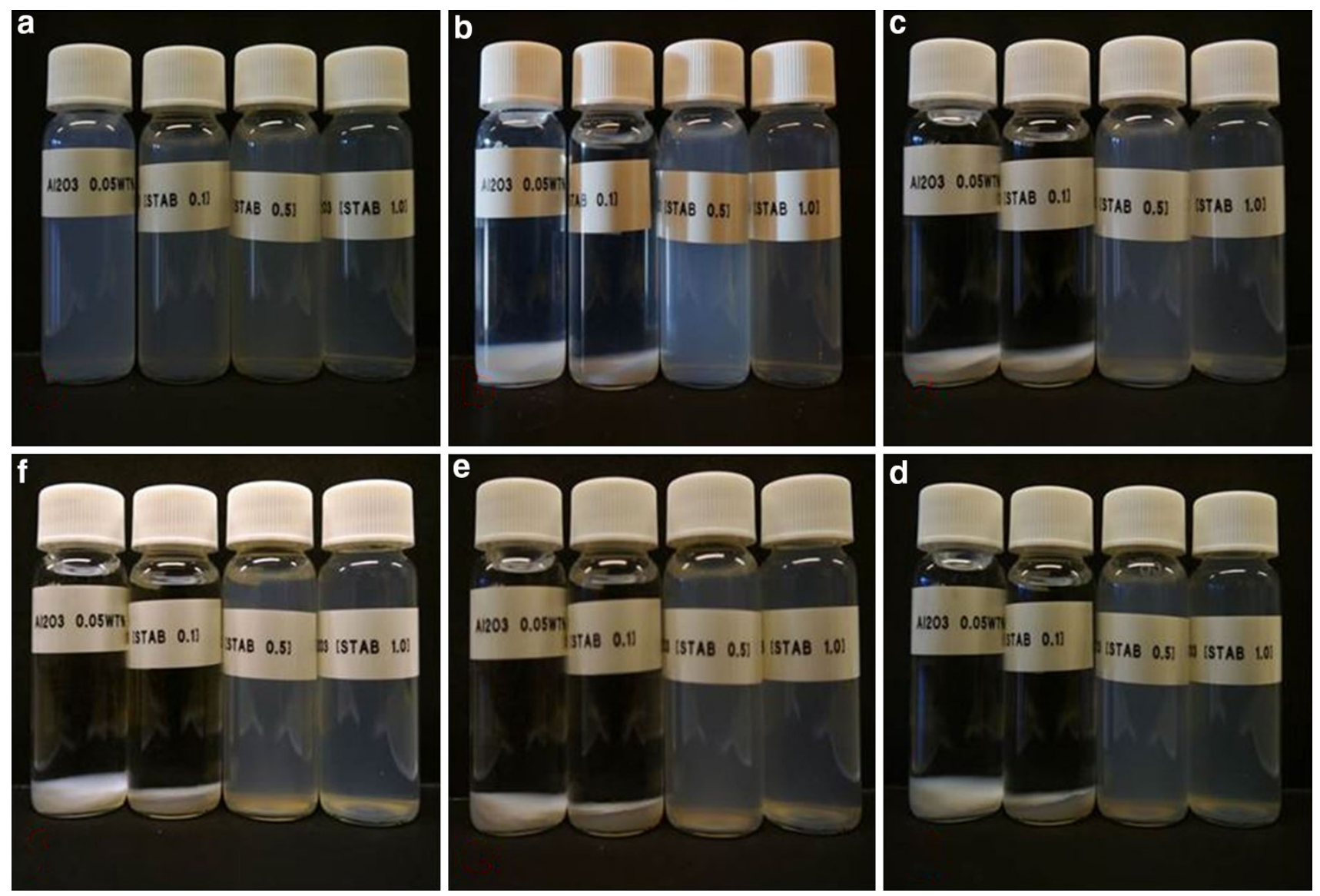

Fig. $14 \mathrm{PVP}$ treated $\mathrm{A} 12 \mathrm{O} 3$ nanofluids stability observations at $50{ }^{\circ} \mathrm{C}$ at different concentrations: $0.0 ; 0.1 ; 0.5$ and $1.0 \mathrm{wt} \%$. a initial condition, b $t=1 \mathrm{~h}, \mathbf{c} t=24 \mathrm{~h}, \mathbf{d} t=72 \mathrm{~h}, \mathbf{e} t=96 \mathrm{~h}, \mathbf{f} t=168 \mathrm{~h}$

The development of three coupled techniques was successful in identifying nanofluid stability.

\section{Effect of adding a stabiliser}

To improve metal oxide nanofluid stability, PVP (Povidone K30) is added at three different weight concentrations of $0.1,0.5$ and $1.0 \mathrm{wt}$. \% but was not added to the silica-based nanofluid because this suspension was considered stable with a mean particle size distribution close to the average single particle size. Visual stability was observed at $50{ }^{\circ} \mathrm{C}$ during a 168-hour period, as shown in Figs. 14, 16. It was observed that PVP provided better stability at particular concentrations. At a low concentration of $0.1 \mathrm{wt} \%$, PVP does not provide any effect on the metal oxide nanofluid stability. Increasing the PVP concentration to $1.0 \mathrm{wt}$ \% provides better stability, and at 1.0 wt. \% of PVP, the nanofluid stability was investigated for more than $96 \mathrm{~h}$ for the $\mathrm{Al}_{2} \mathrm{O}_{3}$-based nanofluid but over shorter time period for the $\mathrm{TiO}_{2}$-based nanofluid, approximately $48 \mathrm{~h}$. However, both conditions showed good stability at higher temperatures, i.e. $50{ }^{\circ} \mathrm{C}$.
Addition of PVP also altered such nanofluid properties as $\mathrm{pH}$ and surface conductivity. Figure 17 shows how PVP significantly changed these nanofluid properties, but density and viscosity were not significantly altered. Higher PVP concentrations caused lower $\mathrm{pH}$ values and higher surface conductivities on metal oxide nanofluids, higher than those of $\mathrm{SiO}_{2}$ nanofluids. At higher PVP concentrations $\left(0.5\right.$ and 1 wt. \%), the surface conductivity of $\mathrm{Al}_{2} \mathrm{O}_{3}$ nanofluids exceeded that of $\mathrm{TiO}_{2}$ nanofluids. The highest conductivity of $\mathrm{Al}_{2} \mathrm{O}_{3}$ is similar only to that of brine with PVP (1 wt. \%). These results are consistent with the visual stability observation in which the $\mathrm{Al}_{2} \mathrm{O}_{3}$ nanofluid with PVP showed better stability than $\mathrm{TiO}_{2}$ nanofluids at the given high PVP concentration. For nanofluid stability, it may be of interest to find a suitable dispersant for each metal oxide NP together with its optimum concentration. Fedele et al. (2011) observed that PEG 600 (Alfa Aesar) is a suitable dispersant for $\mathrm{TiO}_{2}$-based nanofluids.

A dispersant (PVP) with $1 \mathrm{wt}$ \% concentration in metal oxide NPs was selected for the particle size distribution study, as shown in Figs. 18 and 19. The presence of PVP successfully increased the intensity of the mean particle 

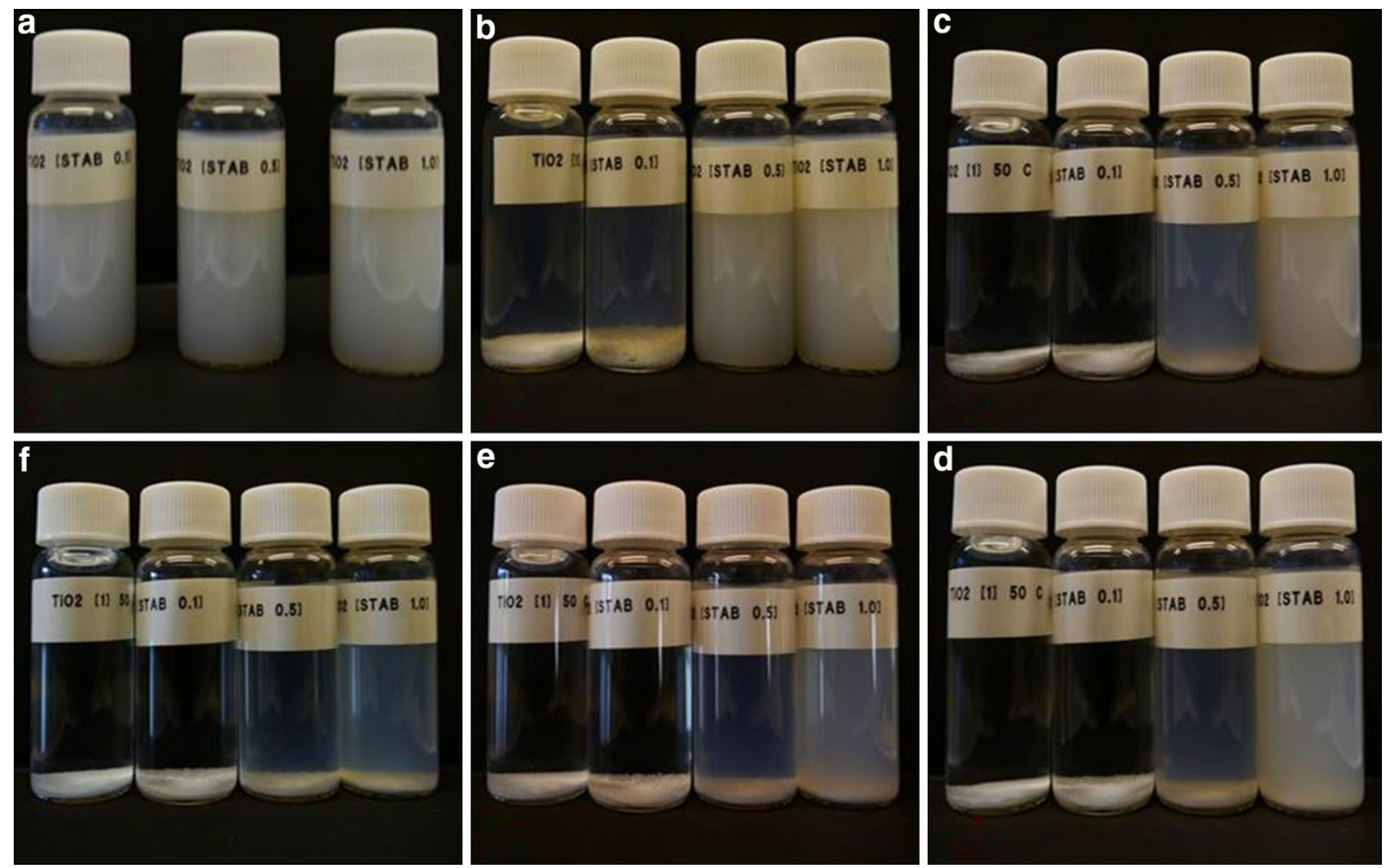

Fig. $16 \mathrm{PVP}$ treated TiO2 nanofluids stability observations at $50{ }^{\circ} \mathrm{C}$ different concentrations: $0.0 ; 0.1 ; 0.5$ and 1.0 wt $\%$. a initial condition, b $t=1 \mathrm{~h}, \mathbf{c} t=24 \mathrm{~h}, \mathbf{d} t=72 \mathrm{~h}, \mathbf{e} t=96 \mathrm{~h}, \mathbf{f} t=168 \mathrm{~h}$

Fig. 17 The $\mathrm{pH}$ and surface conductivity alteration of nanofluids at various PVP concentrations at room condition

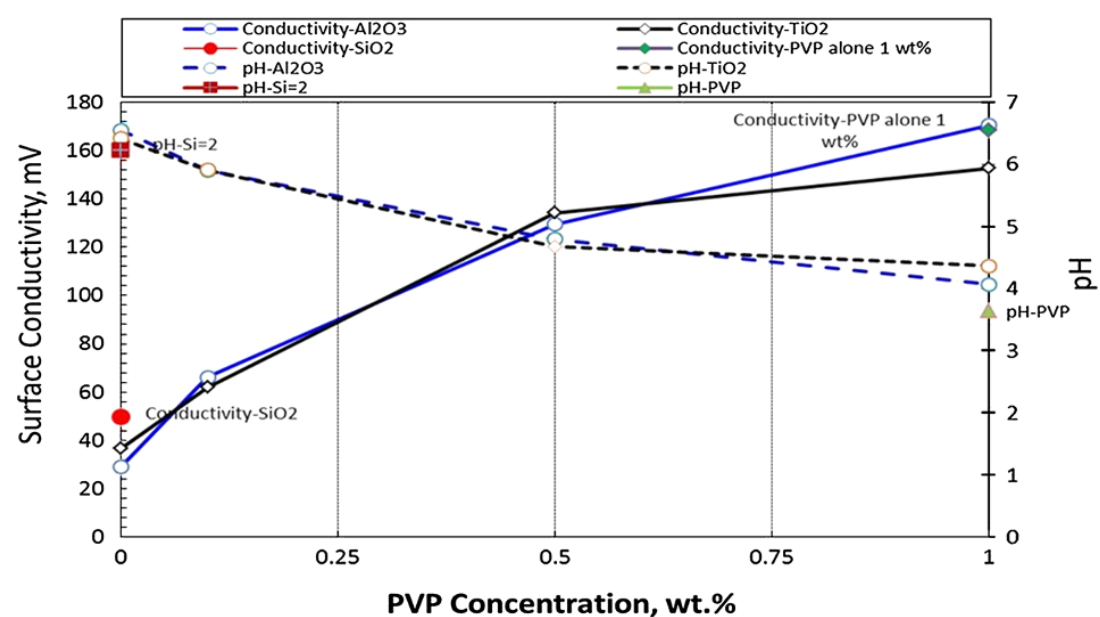

the potential for EOR processes in Berea sandstone, because the nanofluid may easily flow through a core pore throat of micron size.

\section{Coreflood experiment}

The coreflood experiment results from several Berea core plugs are summarised in Table 4. A dispersant (PVP) at 1 wt. \% was added to the metal oxide-based nanofluid based 
Fig. 18 NanoSight

measurement of nanoparticles size distribution for brine $(\mathrm{NaCl}$ $3 \mathrm{wt} \%$ ) containing $0.05 \mathrm{wt} \%$ $\mathrm{Al}_{2} \mathrm{O}_{3}$-based NPs

Fig. 19 NanoSight measurement of nanoparticles size distribution for brine $(\mathrm{NaCl}$ 3 wt $\%$ ) containing 0.05 wt $\%$ $\mathrm{TiO}_{2}$-based NPs

Fig. 15 NanoSight measurement of nanoparticles size distribution for brine $(\mathrm{NaCl}$ $3 \mathrm{wt} \%$ ) containing $0.05 \mathrm{wt} \%$ $\mathrm{SiO}_{2}$-based NPs
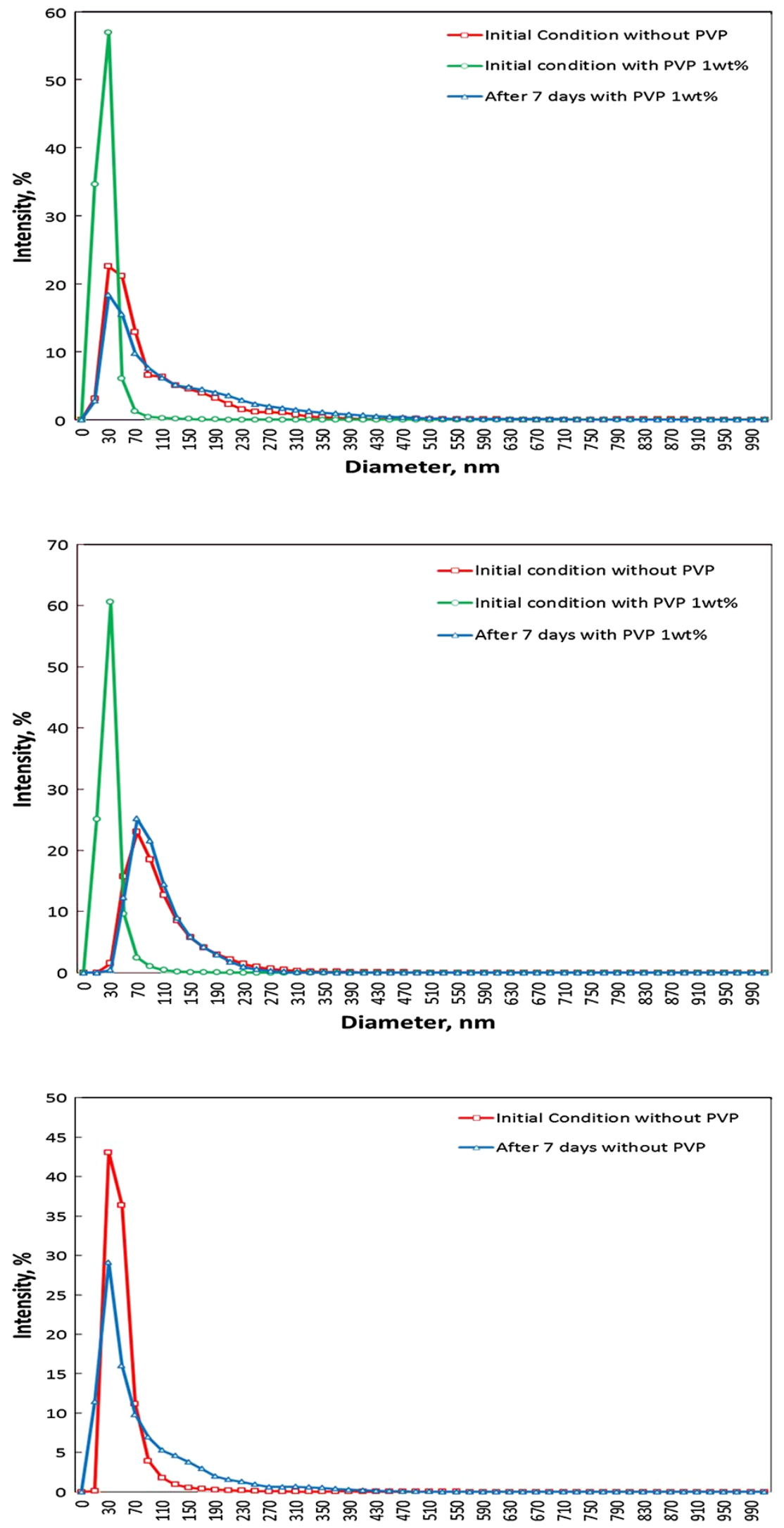

Diameter, nm 
Table 4 Summary of coreflood experiments

\begin{tabular}{|c|c|c|c|c|c|c|c|c|c|}
\hline \multirow[t]{2}{*}{ Core \# } & \multirow{2}{*}{$\begin{array}{l}\text { Initial water } \\
\text { saturation, \% PV }\end{array}$} & \multicolumn{3}{|c|}{ Oil recovery, $\%$ OOIP } & \multicolumn{3}{|c|}{ Residual oil saturation, \% PV } & \multirow{2}{*}{$\begin{array}{l}\text { Total recovery, } \\
\% \text { OOIP }\end{array}$} & \multirow[t]{2}{*}{ Case NF } \\
\hline & & WF1 & $\mathrm{NF}$ & WF2 & WF1 & $\mathrm{NF}$ & WF2 & & \\
\hline $1-W W$ & 19 & 52 & 8 & 6 & 32 & 26 & 23 & 66 & $\mathrm{Al}_{2} \mathrm{O}_{3}$ with PVP \\
\hline $2-W W$ & 20 & 57 & 11 & 9 & 29 & 22 & 16 & 77 & $\mathrm{TiO}_{2}$ with PVP \\
\hline $3-W W$ & 32 & 53 & 2 & 19 & 35 & 33 & 19 & 74 & $\mathrm{SiO}_{2}$ with PVP \\
\hline $4-W W$ & 16 & 55 & 1 & 2 & 30 & 29 & 28 & 58 & PVP alone \\
\hline 5-IW & 32 & 54 & 5 & 6 & 32 & 28 & 24 & 65 & $\mathrm{Al}_{2} \mathrm{O}_{3}$ with PVP \\
\hline 6-IW & 30 & 60 & 4 & 6 & 28 & 25 & 21 & 70 & $\mathrm{TiO}_{2}$ with PVP \\
\hline 7-IW & 31 & 53 & 2 & 16 & 32 & 31 & 20 & 71 & $\mathrm{SiO}_{2}$ with $\mathrm{PVP}$ \\
\hline 8-OW & 22 & 50.9 & 0.4 & 2.3 & 38.2 & 37.9 & 36.1 & 53.5 & $\mathrm{Al}_{2} \mathrm{O}_{3}$ with $\mathrm{PVP}$ \\
\hline 9-OW & 25 & 42 & 6 & 21 & 43 & 39 & 23 & 69 & $\mathrm{TiO}_{2}$ with PVP \\
\hline 10-OW & 27 & 46 & 2 & 25 & 39 & 38 & 19 & 73 & $\mathrm{SiO}_{2}$ with $\mathrm{PVP}$ \\
\hline
\end{tabular}

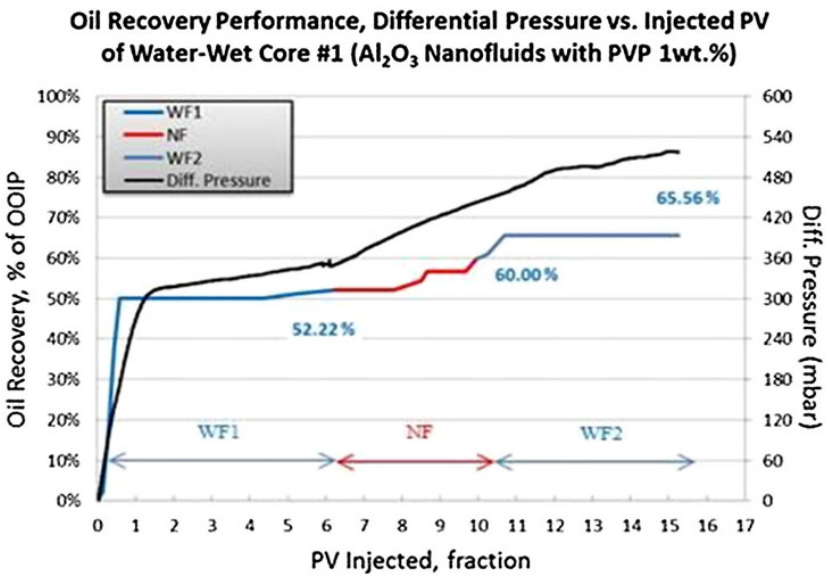

Oil Recovery Performance, Differential Pressure vs. Injected PV of Water-Wet Core \#3 ( $\mathrm{SiO}_{2}$ Nanofluids)

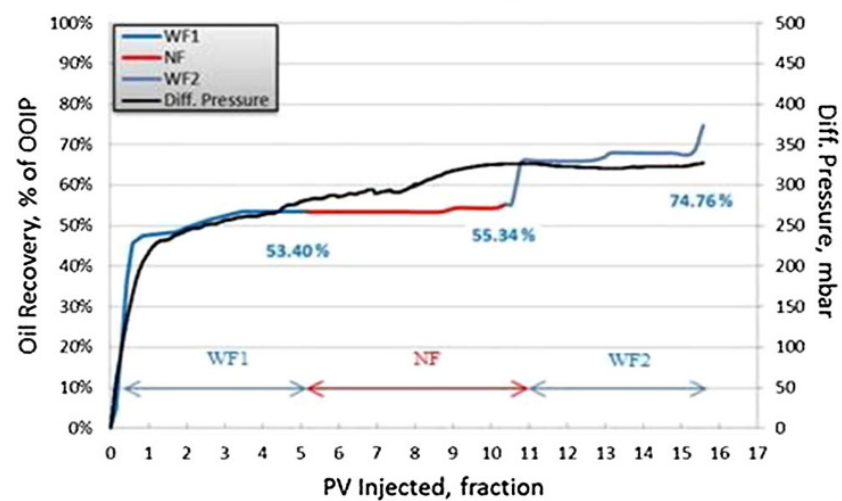

Oil Recovery Performance, Differential Pressure vs. Injected PV of Water-Wet Core \#2 (TiO, Nanofluids with PVP 1wt\%)

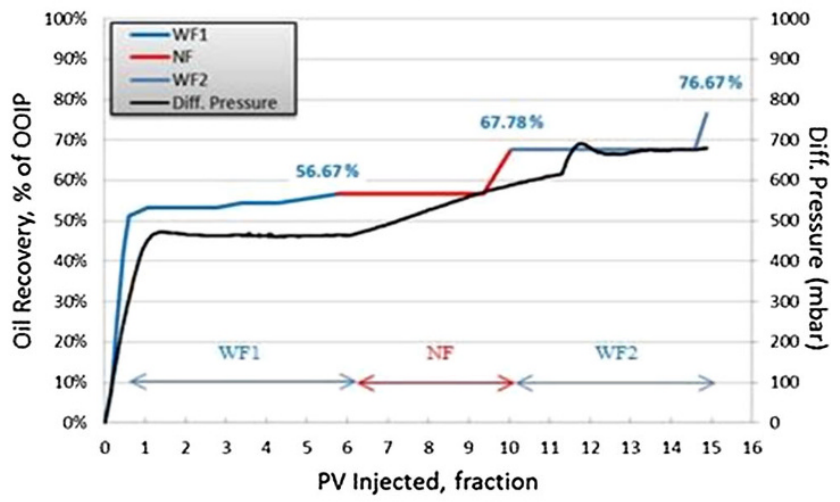

Oil Recovery Performance, Differential Pressure vs. Injected PV of Water-Wet Core \#4 (Brine + PVP alone)

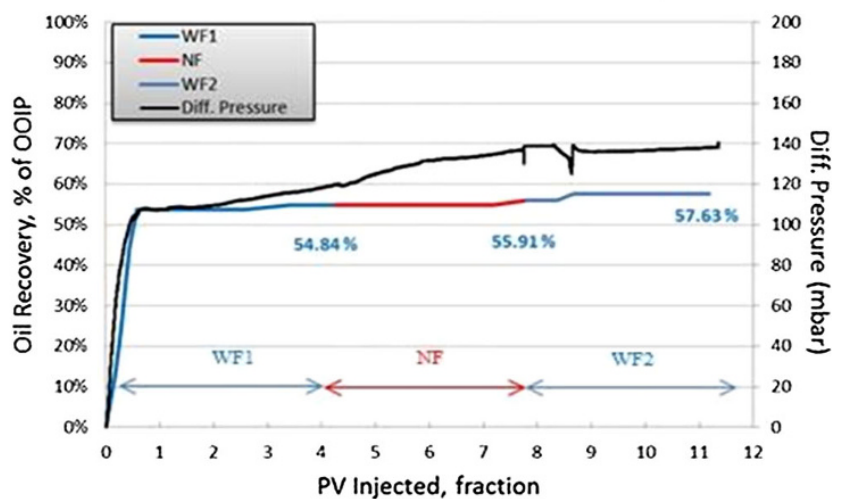

Fig. 20 Oil recovery profile, differential pressure vs. injected PV of water-wet cores

on previous stability analysis. The average oil recoveries after waterflooding with brine (WF1) are in the range of $52-57 \%$ of original oil in place (OOIP) for a water-wet system, 53-60\% of OOIP for an intermediate-wet system and $42-51 \%$ of OOIP for an oil-wet system. Morrow (1985) observed that oil recovery reached a maximum for cores in an intermediate-wet system, which is likely related to disconnection and trapping of the oil phase. After a water cut of $100 \%$, nanofluids were injected as a tertiary recovery process (nano-EOR, denoted as NF). The nanofluids successfully reduced residual oil saturation. However, as shown Figs. 20, 21, 22, the nanofluids 

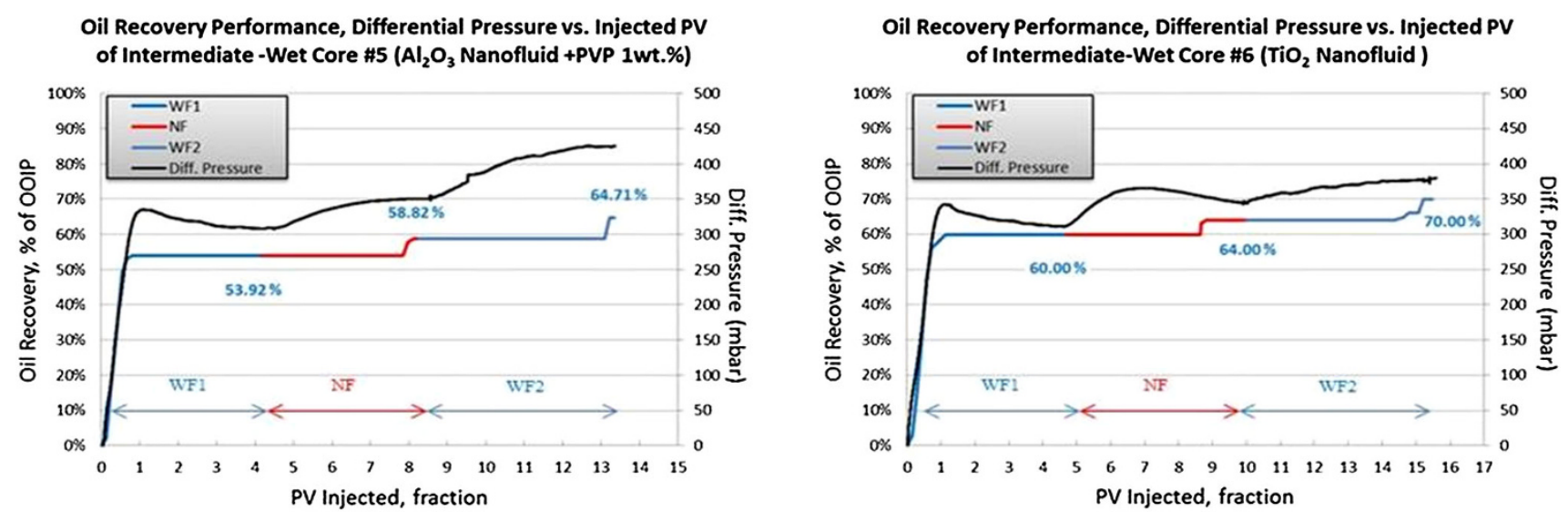

Oil Recovery Performance, Differential Pressure vs. Injected

$\mathrm{PV}$ of Intermediate-Wet Core $\# 7\left(\mathrm{SiO}_{2} \mathrm{Nanofluid}\right)$

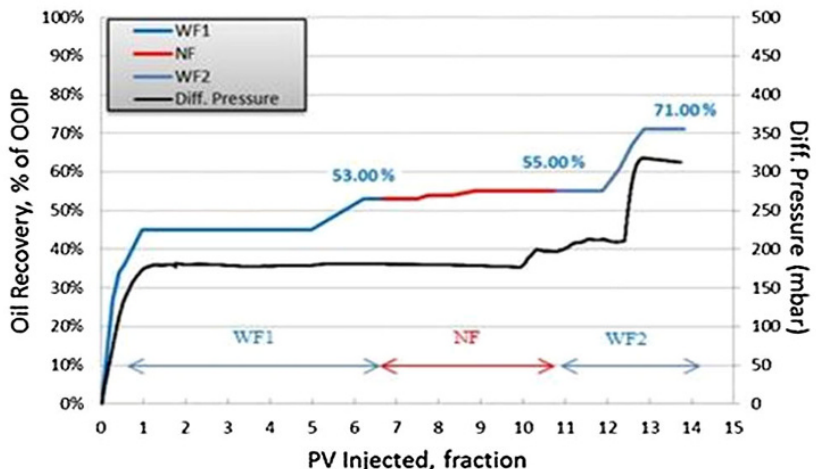

Fig. 21 Oil recovery profile, differential pressure vs. injected PV of intermediate-wet cores

required a certain amount of time to displace additional oil, at least $0.5 \mathrm{PV}$ during NF, likely due to physicochemical interactions between the NPs and the grain surfaces. The additional oil recovery from the NF sequence of both metal oxide-based nanofluids is much greater than that of silicabased nanofluid, especially in a water-wet system. The additional oil recovery (NF) of metal oxide-based nanofluids decreased as the wettability changed from water- to intermediate- and oil-wet systems. However, the $\mathrm{TiO}_{2}$ based nanofluid (with PVP) showed the best performance in this sequence (NF) in all wettability systems. The absence of metal oxide NPs in brine with dispersant solution had no significant impact on the additional oil recovery. Hence, the combination of metal oxides and dispersant shows great potential for EOR. In the last sequence (WF2), brine was re-injected to flush out any remaining particles and might have reduced residual oil in the core. The most interesting result came from the silica-based nanofluid. As shown, the residual oil saturation decreased dramatically from 11 to $19 \%$ points of $\mathrm{PV}$, whereas the oil recovery increased from 19 to $25 \%$ points of OOIP in all wettability systems, and the trend appears identical in all silica-based nanofluid cases. Metal oxide NPS have a greater ability to adsorb into the pore throat than silica NPs, and $\mathrm{pH}$ plays significant role in the trapping mechanism (Ogolo et al. 2013). The effectiveness of particle trapping is greater at lower $\mathrm{pH}$. Both metal oxide-based nanofluids (with PVP) provide much lower $\mathrm{pH}$ values than the silica-based nanofluid and tend to adsorb inside the pore throat rather than washing out during the NF and WF2 sequences. Silica oxide NPs have a low adsorption capacity and are easily washed-out (due to negative charges) and displace more oil. The NP adsorption during transport in a porous medium involves physicochemical interactions between NPs and grain surfaces (Zhang et al. 2013).

Figure 23 shows the filtration mechanism of NPs in Berea sandstone from observation of the inlet point of cores after the WF2 sequence. It is clear that there were no surface nano-cakes formed during NF flooding in all cases (metal oxides with PVP and silica-based nanofluids). Increasing the injection rate may affect the accumulation of NPs at the core inlet (Hendraningrat et al. 2013d). The particle velocity through the porous medium might be lower than the nanofluid injection rate and will create nanocaking (increasing pressure drop) at an injection rate of $0.8 \mathrm{~cm}^{3} / \mathrm{min}$, as shown in Fig. 23d. If the nanofluid 
remains stable at nanometer size, core plugging could be avoided and a physicochemical adsorption mechanism might occur between the particles and the porous medium.

\section{Displacement mechanism}

In this study, several possible measurements, i.e. contact angle, IFT and effluent analyses, were conducted to identify the oil displacement mechanism using metal oxide NPs. Karimi et al. (2012) observed that $\mathrm{ZrO}_{2}$ plays an important role in the wettability alteration of a carbonate reservoir rock, whereas it could also change the wettability of the rock from a strongly oil-wet to strongly water-wet condition. Giraldo et al. (2013) observed that aluminabased nanofluids altered the wettability of cores from an oil-wet to a water-wet condition. Ehtesabi et al. (2014) reported a similar phenomenon in which the rock wettability changed from an oil- to water-wet condition after treatment with $\mathrm{TiO}_{2}$ NPs. Therefore, metal oxide-based nanofluids may change the rock wettability and affect the oil displacement mechanism.

Figure 24 shows the contact angle measurements for different aqueous phases in a water-wet system (a) and an oil-wet system (b). Once the hydrophilic metal oxide (with PVP) is introduced into the brine, it reduces the contact angle from $54^{\circ}$ to $21^{\circ}$, which means that metal oxide-based nanofluids have rendered the quartz plate more strongly water-wet. In contrast, PVP alone rendered the quartz weakly water-wet. The highest reduction in contact angle was achieved with the $\mathrm{TiO}_{2}$-based nanofluid, consistent with the oil recovery results obtained from the $\mathrm{TiO}_{2}$-based nanofluid applied as tertiary recovery (NF) in a water-wet system. Due to the poor clarity of the $\mathrm{TiO}_{2}$-based nanofluid in the oil-wet system, the measurements could not be performed in addition to IFT measurements. Similar to the water-wet system, the presence of hydrophilic NPs in brine tends to change the quartz plate to a weakly oil-wet system. However, the silica-based nanofluid is more effective in an oil-wet system than an $\mathrm{Al}_{2} \mathrm{O}_{3}$-based nanofluid, a result consistent with the observation that additional oil recovery from $\mathrm{SiO}_{2}$-based nanofluid is greater than with $\mathrm{Al}_{2} \mathrm{O}_{3}$ based nanofluid in an oil-wet system.

The IFT was measured at room temperature, as shown in Table 5, and a brine-crude oil system is used with the base value of $19.2 \mathrm{mN} / \mathrm{m}$ and a $\mathrm{pH}$ value of 6.76 . The presence of NPs reduced the IFT between the oleic phase and the aqueous phase as well as the presence of PVP as dispersant. The lowest IFT was achieved with metal oxide NPs, although they do not have the lowest $\mathrm{pH}$. As shown in Fig. 17, the lowest $\mathrm{pH}$ was obtained from brine with PVP solution (approx. pH 3.6), and metal oxide-based nanofluids have a $\mathrm{pH}$ in the range 4-5. Additional oil recovery due to a silica-based nanofluid is greater than that of a brine with PVP solution, even though silica-based nanofluids have a higher IFT than a brine with PVP solution. It can be concluded that the degree of IFT reduction is not a main parameter in oil displacement in nano-EOR.

In addition, the $\mathrm{pH}$ and surface conductivity of the effluent were also analysed, and the results are summarised in Table 6. Based on the measurements, the $\mathrm{pH}$ value and surface conductivity of injected brine were altered in all cores before and after injection of NF. The effluent became more acidic (lower $\mathrm{pH}$ ) and the surface charge increased. This alteration may have occurred due to adsorption of NPs during NPs transport through the porous medium, resulting in wettability alteration. This particle retention during NP transport in porous media has been observed in a previous study (Hendraningrat et al. 2013b). The trend of the $\mathrm{pH}$ value of $\mathrm{Al}_{2} \mathrm{O}_{3}$-based nanofluids after the WF2 sequence is lower than in the NF sequence and has the highest capacity for adsorption into the pore throat amongst the other nanofluids due to the lowest $\mathrm{pH}$. It is observed that $\mathrm{pH}$ plays a significant role in the trapping mechanism, and $\mathrm{Al}_{2} \mathrm{O}_{3}$ is identified as one of the most effective NPs for trapping and migrating in fine sand (Ogolo et al. 2013). However, the $\mathrm{pH}$ reduction is not the main cause of the displacement mechanism, as demonstrated in the case of brine with PVP alone. This solution has the lowest $\mathrm{pH}$ but does not have a significant effect on additional oil recovery for either the NF or WF2 sequences. Although pH induced an IFT reduction, the relationship is not proportional to the additional oil recovery. Hence, wettability alteration plays a dominant role in the oil displacement mechanism using nano-EOR.

\section{Concluding remarks and future work}

A systematic study of hydrophilic metal oxide nanoparticles (NPs) for EOR purposes was performed, and the stability of metal oxide-based nanofluids was successfully improved by adding PVP at $1 \mathrm{wt}$. \%. The PVP altered the fluid properties, i.e. $\mathrm{pH}$ and surface conductivity, and provided better nanofluid stability. The combinations of metal oxide nanofluids and PVP improved oil recovery to a greater extent than silica-based nanofluid and dispersant alone, and the $\mathrm{TiO}_{2}$-based nanofluid was especially effective for all wettability systems. The additional oil recovery (NF) of metal oxide-based nanofluids decreased as the wettability changed from water- to intermediate- and oilwet systems. The contact angle, interfacial tension (IFT) and effluent were measured and analysed in the displacement mechanism observations. It was observed that all nanofluids rendered the quartz plate more water-wet, and the $\mathrm{TiO}_{2}$-based nanofluid was the most effective wettability-altering fluid. This result is consistent with and proportional to the additional oil recovery from the coreflood 
Oil Recovery Performance, Differential Pressure vs. Injected PV of Oil-Wet Core \#8 ( $\mathrm{Al}_{2} \mathrm{O}_{3}$ Nanofluid +PVP 1wt.\%)

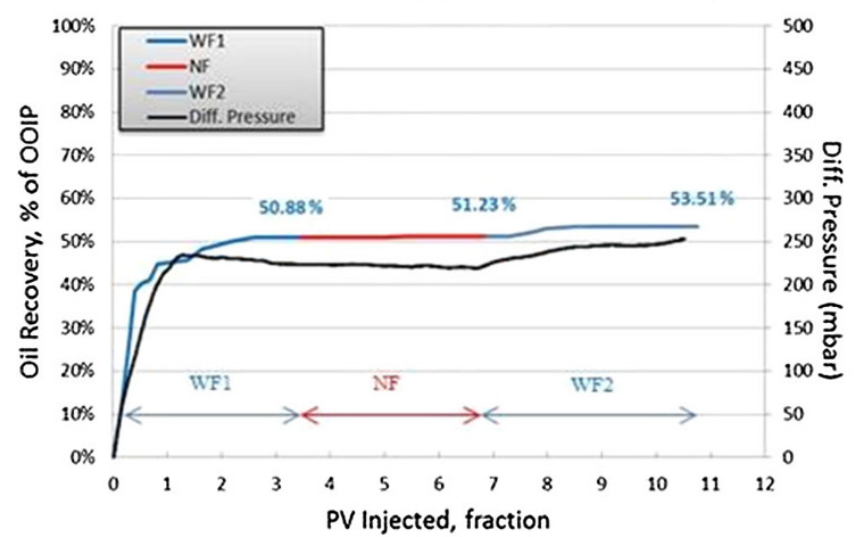

Oil Recovery Performance, Differential Pressure vs. Injected PV of Oil-Wet Core \#9 ( $\mathrm{TiO}_{2}$ Nanofluid +PVP 1wt.\%)

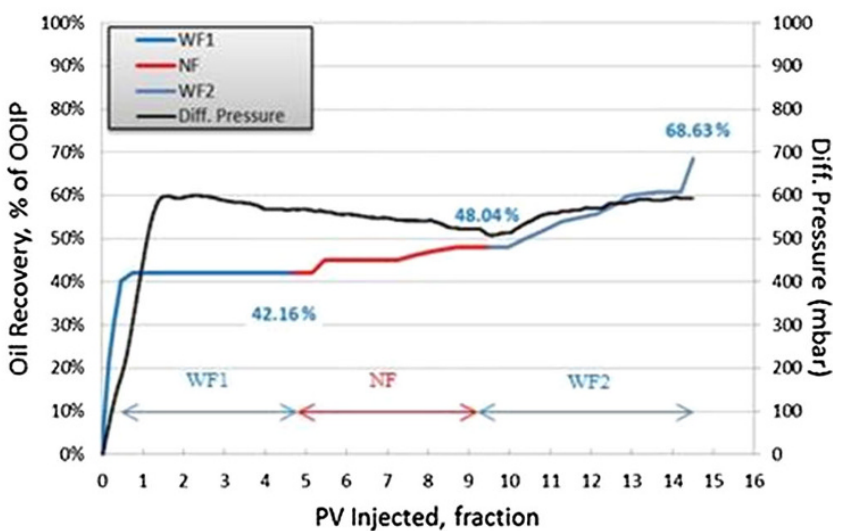

Oil Recovery Performance, Differential Pressure vs. Injected PV of Oil-Wet Core $\# 10$ ( $\mathrm{SiO}_{2}$ Nanofluid)

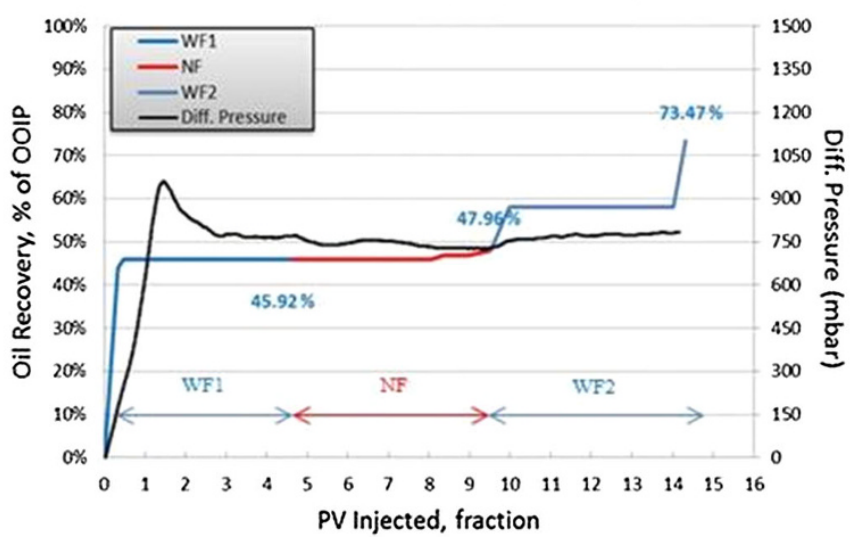

Fig. 22 Oil recovery profile, differential pressure vs. injected PV of oil-wet cores
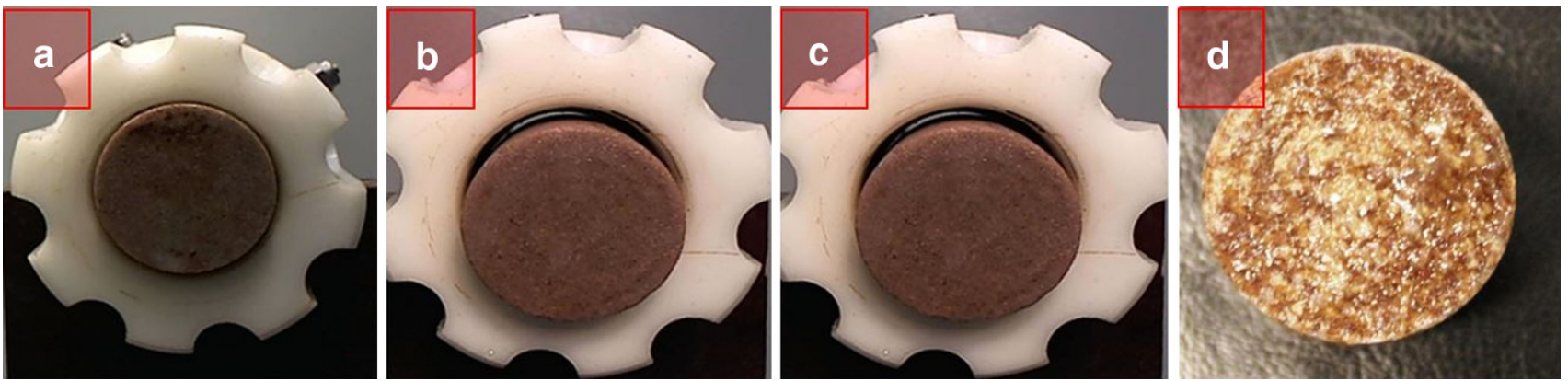

Fig. 23 Core inlet point observation after nanofluid flooding: a $\mathrm{Al}_{2} \mathrm{O}_{3}$-based, $\mathbf{b} \mathrm{TiO}_{2}$-based $\mathbf{c} \mathrm{SiO}_{2}$-based, $\mathbf{d} \mathrm{SiO}_{2}$-based at higher injection rate $\left(0.8 \mathrm{~cm}^{3} / \mathrm{min}\right)$

experiment. The particle adsorption during the transport process was identified from the effluent analysis. The presence of NPs reduced the IFT between the oleic phase and aqueous phase as did the presence of PVP as dispersant, but the degree of IFT reduction is not proportional to the additional oil recovery. The lowest IFT was achieved by metal oxide NPs even though this material does not have the lowest $\mathrm{pH}$. The additional oil recovery due to silica-based nanofluid is greater than that of brine with PVP solution, even though the silica-based nanofluid has a higher IFT than the brine with PVP solution. Therefore, wettability alteration plays a dominant role in the oil 

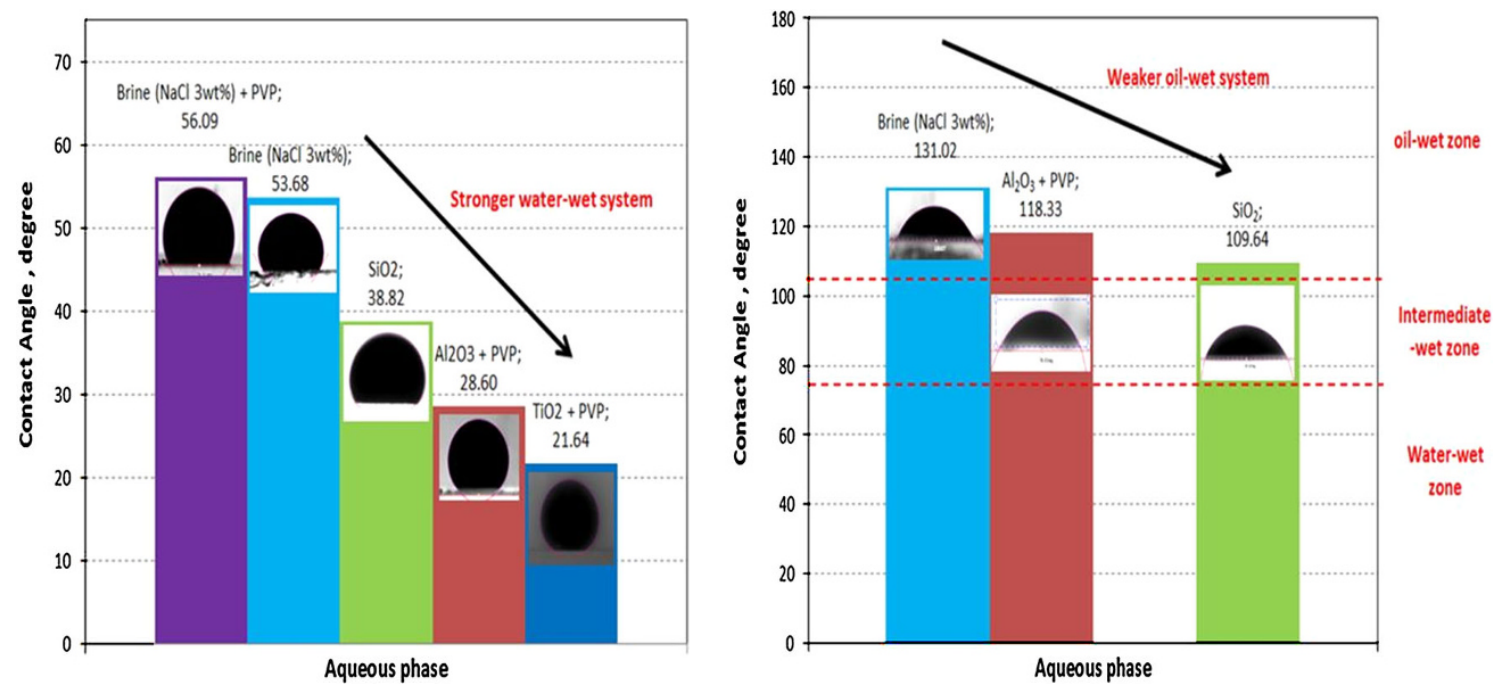

Fig. 24 Contact angle measurement of aqueous phase on quartz plate at room temperature: a water-wet and $\mathbf{b}$ oil-wet system

Table 5 Interfacial tension measurement for aqueous phase against crude oil (at room temperature)

\begin{tabular}{ll}
\hline Fluid & $(\mathrm{mN} / \mathrm{m})$ \\
\hline Brine (NaCl 3 wt. \%) & 19.2 \\
$\mathrm{Al}_{2} \mathrm{O}_{3}$-based (0.05 \% wt.) + PVP 1 wt. \% & 12.8 \\
$\mathrm{TiO}_{2}$-based (0.05 \% wt.) + PVP 1 wt. \% & n.a \\
Silica-based (0.05 \% wt.) & 17.5 \\
Brine (NaCl 3 wt. \%) + PVP 1 wt. \% & 15.7 \\
\hline
\end{tabular}

Table 6 Effluent analysis

\begin{tabular}{|c|c|c|c|c|c|c|}
\hline \multirow[t]{2}{*}{ Core \# } & \multicolumn{3}{|l|}{$\mathrm{pH}$} & \multicolumn{3}{|c|}{ Surface conductivity (mV) } \\
\hline & WF1 & NF & WF2 & WF1 & NF & WF2 \\
\hline 1 & 6.245 & 5.846 & 5.656 & 46.5 & 68.8 & 79.5 \\
\hline 2 & 6.097 & 5.049 & 5.876 & 47.2 & 109.8 & 62.7 \\
\hline 3 & 6.525 & 6.144 & 6.161 & 27.8 & 49.1 & 48.2 \\
\hline 4 & 5.839 & 5.271 & 5.330 & 51.3 & 81.4 & 78.2 \\
\hline 5 & 5.560 & 5.434 & 5.291 & 80.1 & 87.2 & 95.2 \\
\hline 6 & 5.690 & 4.987 & 5.552 & 72.6 & 112.2 & 82.2 \\
\hline 7 & 6.241 & 6.068 & 6.129 & 46.7 & 52.1 & 47.1 \\
\hline 8 & 5.541 & 4.616 & n.a & 63.6 & 112.6 & n.a \\
\hline 9 & 4.748 & 4.52 & 4.53 & 108 & 119.9 & 119.5 \\
\hline 10 & 4.871 & 4.723 & 4.869 & 96.1 & 101.7 & 96.3 \\
\hline
\end{tabular}

displacement mechanism using nano-EOR. Finding a suitable stabiliser for each nanofluid and its optimum concentration might be important in future work as well as repeating the experiment with representative formation water at reservoir conditions.

\section{SI metric conversion factors}

$$
\begin{array}{rr}
\mathrm{mD} \times 9.869233 & \mathrm{E}-04=\mu \mathrm{m}^{2} \\
\mathrm{cP} \times 1.000000 & \mathrm{E}+00=\mathrm{mPa} . \mathrm{s} \\
\mathrm{dyn} / \mathrm{cm} \times 1.000000 \mathrm{E}+00=\mathrm{mN} / \mathrm{m} \\
\text { bar } \times 1.000000 & \mathrm{E}-02=\mathrm{kPa}
\end{array}
$$

Acknowledgments The authors gratefully acknowledge Evonik Industries AG and Elkem Silicon Materials for providing nanoparticles and the Department of Petroleum Engineering and Applied Geophysics, Norwegian University of Science and Technology (NTNU) for financial support necessary to complete this study and permission to publish this article.

Open Access This article is distributed under the terms of the Creative Commons Attribution License which permits any use, distribution, and reproduction in any medium, provided the original author(s) and the source are credited.

\section{References}

Ahmadi M, Habibi A, Pourafshary P (2013) Zeta-potential investigation and experimental study of nanoparticles deposited on rock surface to reduce fines migrations. SPE J 18(3):534-544 (SPE142633-PA)

Anderson WG (1987) Wettability literature survey-part 5: the effects of wettability on relative permeability. $J$ Pet Tech 39(11):1453-1468 (SPE-16323-PA)

Chengara A, Nikolov A, Wasan DT, Trokhymchuck A, Henderson D (2004) Spreading of nanofluids driven by the structural disjoining pressure gradient. J Colloid Interface Sci 280:192-201

Ehtesabi H, Ahadian MM, Taghikhani V, Ghazanfari MH (2014) Enhanced heavy oil recovery in sandstone cores using TiO nanofluids. Energy Fuels 28(1):423-430 
Fedele L, Colla L, Bobbo S, Barison S, Agresti F (2011) Experimental stability analysis of different water-based nanofluids. Nanoscale Res Lett 6:300

Fernandez-Garcia M, Rodriguez JA (2007) Metal oxide nanoparticles. Brookhaven National Laboratory, New York

Folttmann H, Quadir A (2008) Polyvinylpyrrolidone (PVP)-One of the most widely used excipients in pharmaceuticals: an overview. Drug Deliv Technol 8(6):22-27

Giraldo J, Benjumea P, Lopera S, Cortés FB, Ruiz MA (2013) Wettability alteration of sandstone cores by alumina-based nanofluids. Energy fuel 27:3659-3665

Hascakir B, Babadagli T, Akin S (2008) Experimental and numerical modeling of heavy-oil recovery by electrical heating. Paper SPE/ PS/CHOA 117669-MS presented at the international thermal operations and heavy oil symposium, Calgary, Canada, 20-23 October 2008

Hendraningrat L, Shidong L, Torsæter O (2012) A glass micromodel experimental study of hydrophilic nanoparticles retention for EOR project. Paper SPE 159161-MS presented at the SPE Russian oil \& gas exploration \& production technical conference and exhibition, Moscow, Russia, 16-18 October 2012

Hendraningrat L, Li S, Torsæter O (2013a) A coreflood investigation of nanofluid enhanced oil recovery. J Petrol Sci Eng 111:128-138

Hendraningrat L, Engeset B, Suwarno S, Li S, Torsæter O (2013b) Laboratory investigation of porosity and permeability impairment in Berea sandstones due to hydrophilic nanoparticle retention. Paper SCA2013-062 presented at the international symposium of the society of core analysts held in Napa Valley, California, USA, 16-19 September 2013

Hendraningrat L, Li S, Torsæter O (2013c) A coreflood investigation of nanofluid enhanced oil recovery in low-medium permeability Berea sandstone. Paper SPE 164106-MS presented at SPE international symposium on oilfield chemistry, The Woodlands, Texas, 8-10 April 2013

Hendraningrat L, Li S, Torsæter O (2013d) Effect of some parameters influencing enhanced oil recovery process using silica nanoparticles: an experimental investigation. Paper SPE-165955 presented at SPE Reservoir Characterisation and Simulation Conference and Exhibition, Society of Petroleum Engineers, Abu Dhabi, UAE, 16-18 September 2013

Ju B, Tailiang F, Mingxue M (2006) Enhanced oil recovery by flooding with hydrophilic nanoparticles. China Particuology 4:41-46

Karimi A, Fakhroueian Z, Bahramian A, Khiabani NP, Darabad JB, Azin R, Arya S (2012) Wettability alteration in carbonates using zirconium oxide nanofluids: EOR Implications. Energy Fuels 26(2):1028-1036

Keblinski P, Prasher R, Eapen J (2008) Thermal conductance of nanofluids: is the controversy over? Nanopart Res 10:1089

Keller AA, Wang H, Zhou D, Lenihan HS, Cherr G, Cardinale BJ, Miller R, Ji Z (2010) Stability and aggregation of metal oxide nanoparticles in natural aqueous matrices. Environ Sci Technol 44(6):1962-1967

Li W, Zhu J, Qi J (2007) Application of nano-nickel catalyst in the viscosity reduction of Liaohe extra-heavy oil by aqua-thermolysis. J Fuel Chem 35(2):176-180

Li S, Kaasa AT, Hendraningrat L, Torsæter O (2013). Effect of silica nanoparticles adsorption on the wettability index of Berea sandstone. Paper SCA2013-059 presented at the international symposium of the society of core analysts held in Napa Valley, California, USA, 16-19 September 2013
Miranda CR, De Lara LS, Tonetto BX (2012) Stability and mobility of functionalized silica nanoparticles for enhanced oil recovery application. Paper SPE 157033-MS presented at SPE international oilfield technology conference, Noordwijk, The Netherlands, 12-14 June 2012

Morrow NR (1985) A review of the effects of initial saturation, pore structure, and wettability on oil recovery by waterflooding. In: Proceeding of the north sea oil and gas reservoirs seminar. Graham and Trotman, Ltd: 179-191, Trondheim, Norway, 2-4 December 1985

Morrow NR (1990) Wettability and its effect on oil recovery. J Pet Tech 42(12):1476-1484 (SPE-21621-PA)

Nanosight (2009) Operating manual. NanoSight Ltd., UK

Ogolo NA, Onyekonwu MO Akaranta O (2013) Trapping mechanism of nanofluids on migrating fines in sand. Paper SPE 167502-MS presented at the Nigeria annual international conference and exhibition, Lagos, Nigeria, 30th July-1st August 2013

Ogolo NA, Olafuyi OA, Onyekonwu MO (2012) Enhanced oil recovery using nanoparticles. Paper SPE 160847-MS presented at the SPE Saudi Arabia section technical symposium and exhibition, Al-Khobar, Saudi Arabia, 8-11 April 2012

Rao Y (2010) Nanofluids: stability, phase diagram, rheology and applications. Particuology 8:549-555

Roustaei A, Saffarzadeh S, Mohammadi M (2012) An evaluation of modified silica nanoparticles' efficiency in enhancing oil recovery of light and intermediate oil reservoirs. Egypt $\mathbf{J}$ Petrol 22(3):427-433

Shokrlu YH, Babadagli T (2010) Effects of nano-sized metals on viscosity reduction of heavy oil/bitumen during thermal applications. Paper CSUG/SPE 137540-MS presented at the Canadian unconventional resources and international petroleum conference, Calgary, Canada, 19-21 October 2010

Than P, Preziosi D, Joseph D, Arney M (1988) Measurement of interfacial tension between immiscible liquids with the spinning rod tensiometer. J Colloid Interface Sci 124(2):552-559

Torsæter O, Abtahi M (2003) Experimental reservoir engineering laboratory workbook. Department of Petroleum Engineering and Applied Geophysics, Norwegian University of Science and Technology (NTNU), Trondheim

Treiber LE, Duane LE, Archer L, Owens WW (1971) A laboratory evaluation of the wettability of fifty oil-producing reservoirs. SPE J 12:531-540

Wasan DT, Nikolov A (2003) Spreading of nanofluids on solids. J Nat 423:156-159

Wasan DT, Nikolov A, Kondiparty K (2011) The wetting and spreading of nanofluids on solids: role of the structural disjoining pressure. Curr Opin Colloid Interface Sci 16:344-349

Wu W, He Q, Jiang C et al (2008) Magnetic iron oxide nanoparticles: synthesis and surface functionalization strategies. Nanoscale Res Lett 3:397-415

Yu W, France DM, Routbort JL, Choi SUS (2008) Review and comparison of nanofluid thermal conductivity and heat transfer enhancements. Heat Transfer Eng 29:432

Zhang T, Murphy M, Yu H, Bagaria H, Nielson B, Bielawski C, Johnston K, Huh C, Bryant S (2013) Investigation of nanoparticle adsorption during transport in porous media. Paper SPE 166346-MS presented at the SPE annual technical conference and exhibition, New Orleans, Lousiana, 30th September-2nd October 2013 